\title{
Alternative Antimicrobial Approach: Nano-Antimicrobial Materials
}

\author{
Nurit Beyth, ${ }^{1}$ Yael Houri-Haddad, ${ }^{1}$ Avi Domb, ${ }^{2}$ Wahid Khan, ${ }^{3}$ and Ronen Hazan ${ }^{4,5}$ \\ ${ }^{1}$ Department of Prosthodontics, The Hebrew University-Hadassah School of Dental Medicine, P.O. Box 12272, 91120 Jerusalem, Israel \\ ${ }^{2}$ Department of Medicinal Chemistry, School of Pharmacy, Faculty of Medicine, The Hebrew University of Jerusalem, \\ P.O. Box 12065, 91120 Jerusalem, Israel \\ ${ }^{3}$ Department of Pharmaceutics, National Institute of Pharmaceutical Education \& Research (NIPER), Balanagar, \\ Hyderabad 500 037, India \\ ${ }^{4}$ Institute of Dental Sciences, The Hebrew University-Hadassah School of Dental Medicine, P.O. Box 12272, 91120 Jerusalem, Israel \\ ${ }^{5}$ IYAR, The Israeli Institute for Advanced Research, Tel Aviv, Israel
}

Correspondence should be addressed to Nurit Beyth; nuritb@ekmd.huji.ac.il

Received 12 January 2015; Accepted 23 February 2015

Academic Editor: Nianping Feng

Copyright (C) 2015 Nurit Beyth et al. This is an open access article distributed under the Creative Commons Attribution License, which permits unrestricted use, distribution, and reproduction in any medium, provided the original work is properly cited.

Despite numerous existing potent antibiotics and other antimicrobial means, bacterial infections are still a major cause of morbidity and mortality. Moreover, the need to develop additional bactericidal means has significantly increased due to the growing concern regarding multidrug-resistant bacterial strains and biofilm associated infections. Consequently, attention has been especially devoted to new and emerging nanoparticle-based materials in the field of antimicrobial chemotherapy. The present review discusses the activities of nanoparticles as an antimicrobial means, their mode of action, nanoparticle effect on drug-resistant bacteria, and the risks attendant on their use as antibacterial agents. Factors contributing to nanoparticle performance in the clinical setting, their unique properties, and mechanism of action as antibacterial agents are discussed in detail.

\section{Introduction}

Bacterial infections are still a major cause of morbidity and mortality. The growing concern regarding multidrugresistant bacterial strains and biofilm-associated infections calls for the development of additional bactericidal means. Consequently, attention has been especially devoted to new and emerging nanoparticle-based materials in the field of antimicrobial chemotherapy.

Bacteria are naturally found in clinical and industrial settings in association with surfaces. Although modern microbiological research focuses mainly on pure culture planktonic (free-swimming) bacteria, it is now generally recognized that most bacteria live in microbial communities, which are often composed of multiple species that interact with each other and their environment. Bacterial surface contamination, the adhesion, persistence, and colonization of surfaces by bacteria, is increasingly recognized as detrimental to health and society [1]. Biofilm-associated infectious diseases account for over 80 percent of microbial infections in the body, resulting in increased patient morbidity and medical expenses [2].

Biofilms are agglomerates of microorganisms that adhere to a substrate. First, the bacteria bind reversibly to the surface and then secrete binding molecules such as adhesion proteins that cause irreversible attachment. Once settled, the bacteria proliferate and form colonies inside peptidoglycan envelopes, which leads to the development of a mature biofilm. At this stage the bacteria not only become inaccessible to antibacterial agents and the body's immune system, but also provide a reservoir of bacteria for chronic infections throughout the body [3]. This is why biofilms are a severe health threat. Moreover, biofilms respond poorly to conventional antibiotics and may develop antibiotic resistance [2]. 


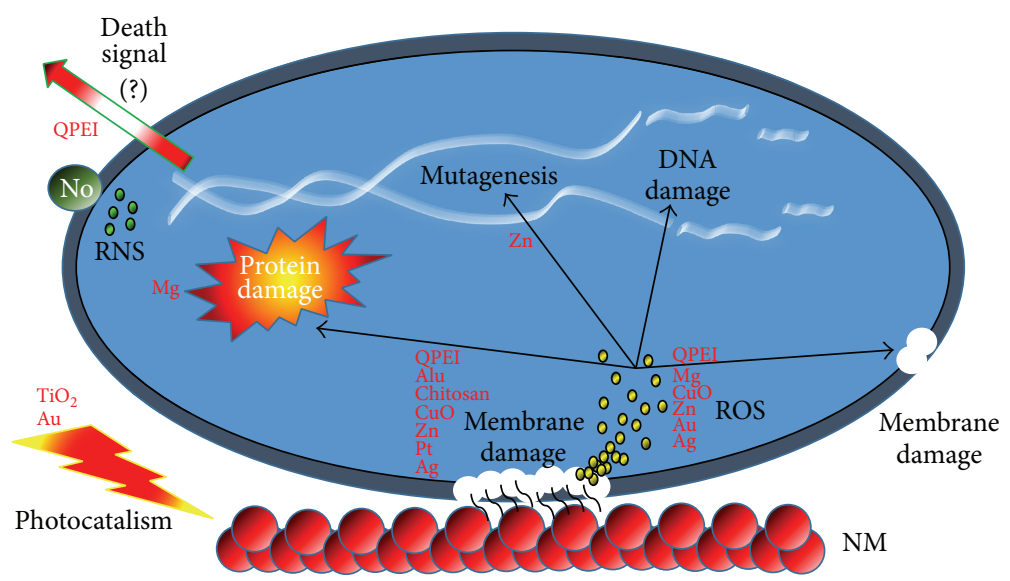

Scheme 1: NM antibacterial mode of action. General schematic depicting the common modes of action of NM. Most known antibacterial NM interact electrostatically with the bacterial membrane causing membrane disruption. Frequently, free radicals (ROS yellow spots) are produced due to the NM-membrane interactions. These radicals may instigate secondary membrane damage, hinder protein function, cause DNA destruction, and result in excess radical production. Other antibacterial NM are photoactivated (photocatalism). Nitric oxide (NO) NM are involved with RNS (green spots). Polycationic NM (QPEI) have a unique feature as they seem to induce signal secretion that may promote programmed cell death.

Thus, despite the numerous existing potent antibiotic drugs and other modern antibacterial means, bacterial infections are still a challenge.

Antimicrobial materials used in the clinical setting today are beset by significant shortfalls, including weak antimicrobial activities, risk of microbial resistance, difficulty in monitoring and extending the antimicrobial functions, and difficulty in functioning in a dynamic environment. Thus, effective and long-term antibacterial and biofilm-preventing materials constitute an immediate need in medicine and dentistry. Today, most biofilm-associated infections are treated with antibiotics for lack of a better alternative. However, it is well established that attacking mature biofilms with conventional antibiotics does not work; that is, much higher than usual drug doses are required, as all such agents have difficulty in penetrating the extracellular polysaccharide sheath covering the biofilm. Biofilm-associated bacteria are 100 to 1,000 times less susceptible to antibiotics than planktonic bacteria, and agents active against planktonic bacteria, but not against biofilms, fail to cure patients [4]. Moreover, high doses are often not tolerated by the host organism, whereas the conventionally used lower doses are inefficient. In addition, the use of conventional antibiotics carries a major risk for resistance of viable bacteria. This issue becomes more complicated in situations where mixed bacterial biofilms are produced and where multiple antibiotics are used to target the complex microflora. Consequently, different measures of antimicrobial protection are required. Nanotechnology today provides a sound platform for adjusting the physicochemical properties of numerous materials to generate effective antimicrobials [5]. Nanomaterials (NM) may be strategically advantageous as active antibacterial groups since their surface area is exceedingly large relative to their size. Nanosized particles may provide high activity although only a small dose of the particles is used. Consequently, NM could serve as an alternative to antibiotics to control bacterial infections.

The major groups of antibiotics, currently in use, generally affect three bacterial targets: cell wall synthesis, translational machinery, and DNA replication [6]. Unfortunately, bacterial resistance may develop against each one of these modes of action. Mechanisms of resistance include enzymes that modify or degrade the antibiotic such as $\beta$-lactamases and aminoglycosides, modification of cell components such as cell wall as seen in vancomycin resistance [6] and ribosomes in tetracyclines resistance, and finally efflux pumps that provide multidrug resistance against numerous antibiotics [6]. Since nanoparticles' mode of action is mainly by direct contact with the bacterial cell wall, without the need to penetrate the cells, most of the resistance mechanisms seen with antibiotics are irrelevant. This raises the hope that nanoparticles would be less prone than antibiotics to promote resistant bacteria.

In this review the potential of various NM as antimicrobial agents is described. The antibacterial mechanism of action of nanoparticles and their interactions with microbial cells leading to cell death, including a detailed discussion of toxic and biocompatibility properties, is provided.

\section{Antimicrobial Nanoparticles}

Nanomaterials as antibacterials complementary to antibiotics are highly promising and are gaining large interest as they might fill the gaps where antibiotics frequently fail. This includes combatting multidrug-resistant mutants and biofilm $[7,8]$. Antimicrobial NM now in use (i.e., metal, metal oxide, and organic nanoparticles) show a diversity of intrinsic and modified chemical composition properties. Thus, it is not surprising that they have numerous modes of action (Scheme 1). 
Furthermore, the target bacteria vary greatly in their genetics and consequently in their cell wall structure, essential metabolic pathways, and many components that when disrupted could be lethal to the microorganisms. Also, the physiological state of the bacteria, that is, planktonic, biofilm, growth rate, stationary, or starved, may greatly contribute to the sensitivity of the bacteria to NM $[9,10]$. In some cases the ratio between the bacteria and the NM is critical to the latter's toxicity [11]. In addition, many environmental factors play a role and affect the lethality of NM to bacteria including aeration, $\mathrm{pH}$, and temperature. The physicochemical properties of the particles including size, shape, chemical modification and coating, and mixture in various ratios with other nanoparticles and solvent used all affect greatly their antibacterial activity [12]. Thus, with this complexity, no wonder that large parts of the NM antibacterial mode of action and level of hazard they pose are still obscure and one can find in the literature contradictory reports about them $[13,14]$.

Nevertheless, in general, NM act along two major lethal pathways, which are related to each other and in many cases occur simultaneously: (1) disruption of membrane potential and integrity and (2) production of reactive oxygen species (ROS), also known as oxygen-free radicals, the NM acting as nanocatalysts $[7,11,15]$.

Membrane damage occurs when NM bind electrostatically to the bacterial cell wall and membranes, leading to alteration of membrane potential, membrane depolarization, and loss of integrity which, in turn, result in an imbalance of transport, impaired respiration, interruption of energy transduction and/or cell lysis, and eventually cell death [7]. ROS, considered the most effective determinant for both the in vitro and in vivo cytotoxicity of NM, are induced indirectly due to respiratory chain disruption or directly by the NM themselves [16]. A burst of ROS causes, via severe oxidative stress, damage to all the cell's macromolecules, leading to lipid peroxidation, alteration of proteins, inhibition of enzymes, and RNA and DNA damage. At high concentrations the ROS lead to cell death and at low doses cause severe DNA damage and mutations $[17,18]$. In some cases, where the production of ROS is induced by visible or UV light [19] the toxicity of $\mathrm{NM}$ is photocatalytic. For instance, $\mathrm{TiO}_{2} \mathrm{NM}$ were shown to induce, under near-UV light, lipid peroxidation which leads to respiratory dysfunction and death of E. coli cells [20].

Several other effects of NM include direct inhibition of specific essential enzymes, induction of nitrogen reactive species (NRS) $[7,11,14,15]$, and induction of programmed cell death [21].

\section{Inorganic Nanoparticles}

Metals and metal oxides have been widely studied for their antimicrobial activities [22]. Metal oxide nanoparticles, well known for their highly potent antibacterial effect, include silver $(\mathrm{Ag})$, iron oxide $\left(\mathrm{Fe}_{3} \mathrm{O}_{4}\right)$, titanium oxide $\left(\mathrm{TiO}_{2}\right)$, copper oxide $(\mathrm{CuO})$, and zinc oxide $(\mathrm{ZnO})$. Most metal oxide nanoparticles exhibit bactericidal properties through reactive oxygen species (ROS) generation although some are effective due to their physical structure and metal ion release.
Representative synthesis/preparation of selected antimicrobial NM is shown in Table 1.

3.1. Silver. Of the metal nanoparticles, silver nanoparticles have been widely used as an effective antimicrobial agent against bacteria, fungi, and viruses [23]. Their effect was recognized already in ancient times. Ag and its compounds have long been used for the disinfection of medical devices and water purification. In medicine, Ag compounds are commonly applied to treat burns, wounds, and a variety of infectious diseases [24-26]. The antimicrobial efficacy of Ag, as of other metals and metal oxide nanoparticles, was reported to be size-dependent [27]. Although the Ag nanoparticle mechanism of action is still not clear, small diameter $\mathrm{Ag}$ nanoparticles have a superior antimicrobial effect to those of a larger diameter [28]. Moreover, Ag nanoparticle antibacterial activity exceeds that of their bulk equivalents. Nonetheless, high surface energy may compromise their efficacy due to their susceptibility to aggregate into large particles, which may result in the loss of their antibacterial activity.

Silver (Ag), similarly to other nonantibiotic treatments, was almost abandoned when penicillin and later on other antibiotics were discovered. But today, with the emergence of antibiotic-resistant strains, it has gained new, yet controversial, interest [29]. Silver was reported to be an efficient bactericidal antibacterial agent against various pathogens in vitro and in vivo [30]. Moreover, it seems that bacteria are less prone to develop resistance against $\mathrm{Ag}$ than against conventional antibiotics $[31,32]$. However, several points of controversy remain to be resolved: the debate and questions on the definition and determination of silver minimal inhibitory concentration (MIC) and breaking point, the ease of emergence of resistant strains $[33,34]$, whether silver really kills biofilm or just planktonic cells [35], and the side effects of Ag on humans [36-38]. In addition, the bactericidal mechanisms of Ag-NM are not fully understood [39]. In E. coli, as a representative of Gram-negative bacteria, Ag nanoparticles were shown to cause "pits" in the cell wall by increasing the membrane permeability and inactivating the respiratory chain $[21,40]$. Other investigations showed that the Ag ion, which has an affinity for sulfur and nitrogen, can inhibit and disrupt protein structure by binding to thiol and amino groups [41]. Finally it was suggested that silver NM are photocatalytic [42] and can induce ROS [43-45], an observation that was contradicted by others showing that, at least in eukaryotic cells, this effect is cell-type dependent [46, 47]. Ag-NM were shown also to have synergistic antibacterial effects both on Gram-positive and Gram-negative bacteria when provided in combination with antibiotics [48, 49]. However, despite the controversies and ongoing debates, Ag$\mathrm{NM}$ are perhaps the most promising antibacterial metal NM.

3.2. Titanium Oxide. Titanium dioxide $\left(\mathrm{TiO}_{2}\right)$ is another metal oxide that has been extensively studied for its antimicrobial activities [50]. $\mathrm{TiO}_{2}$ has long been known for its ability to kill both Gram-positive and Gram-negative bacteria [51]. More recent reports have shown its efficiency against various viral species and parasites [52-54]. 


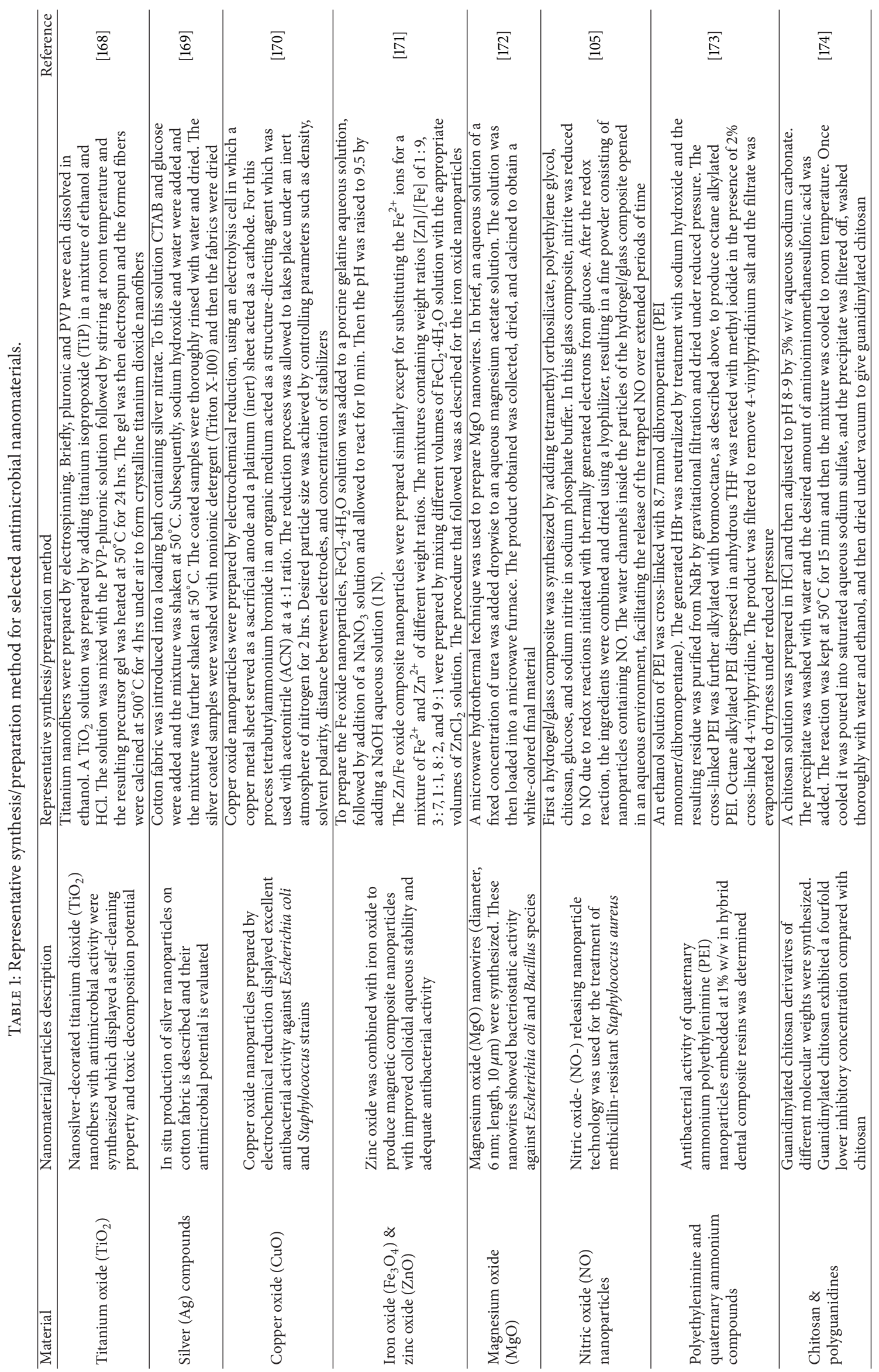


Titanium dioxide $\left(\mathrm{TiO}_{2}\right) \mathrm{NM}$ as antibacterial compounds have been on the market for quite some time [20]. Similar to $\mathrm{Au}$, they are photocatalytic; their toxicity, induced by visible light, near-UV or UV [7], stimulates ROS burst. The ROS damage the membrane, DNA, and many other macromolecules and functions of the bacterial cell [15]. $\mathrm{TiO}_{2}$ is effective against many bacteria including spores of Bacillus [55], which is the most resistant organism known. As with other NM, combinations of $\mathrm{Ti}$ or $\mathrm{TiO}_{2}$ with other NM such as $\mathrm{Ag}$ were found to have a synergistic effect and to enhance their activity [56-58].

3.3. Zinc Oxide. Additional broad spectrum bactericidal NM are $\mathrm{ZnO}$-based nanoparticles [59]. $\mathrm{ZnO}$ nanoparticles were shown to have a wide range of antimicrobial activity against various microorganisms, which is significantly dependent on the chosen concentration and particle size [59]. Moreover, $\mathrm{ZnO}$ nanoparticles were shown to inhibit the growth of methicillin-sensitive $S$. aureus (MSSA), methicillin-resistant $S$. aureus (MRSA), and methicillin-resistant S. epidermidis (MRSE) strains and proved to be effective bactericidal agents that were not affected by the drug-resistant mechanisms of MRSA and MRSE [60,61]. Zinc oxide ( $\mathrm{ZnO}) \mathrm{NM}$ are of relatively low cost [11] and effective in size dependency [59] against a wide range of bacteria $[62,63]$. These include pathogens such as Klebsiella pneumonia [64], Listeria monocytogenes, Salmonella enteritidis [65], Streptococcus mutans, Lactobacillus [66], and E. coli $[65,67]$ with low toxicity to human cells [68]. Their white color, UV-blocking, and ability to prevent biofilm formation makes them suitable for fabric [69] and glass [70] industries as coating materials designated for medical and other devices. Furthermore, treatment using zinc was approved by the FDA and nowadays $\mathrm{Zn}$ is available as a food additive [15].

ZnO NM affect bacterial cells along the two pathways, described above, by binding to membranes, disrupting their potential and integrity, and by inducting ROS production $[65,67,71]$. In addition and as a result, Zn NM are also mutagens, albeit weak ones [17].

3.4. Iron Oxide and Gold. $\mathrm{Fe}_{3} \mathrm{O}_{4}$ nanoparticles and gold ( $\left.\mathrm{Au}\right)$ represent an additional class of antimicrobial materials that are being researched for their use in health care [72]. $\mathrm{Fe}_{3} \mathrm{O}_{4}$ in its bulk form and $\mathrm{Au}$ are generally considered inert and lack antimicrobial properties. Interestingly, these materials can be modified to introduce antimicrobial properties when synthesized as nanosize particles. Microbiological assays have proved that surfaces modified using $\mathrm{Fe}_{3} \mathrm{O}_{4}$ nanoparticles demonstrate antiadherent properties and significantly reduce both Gram-negative and Gram-positive bacterial colonization [73]. Au nanoparticles and nanorods have been reported to be bactericidal when photothermally functionalized [74].

In comparison to Ag, gold- (Au-) NM are less potent and have almost no antibacterial effect by themselves [39]. Nevertheless, Au-NM bound to antibiotics such as ampicillin $[75,76]$, vancomycin [77], the antibacterial enzyme lysozyme [78], and even other NM [79] were bactericidal to many multidrug-resistant pathogens, including those which were penicillin and vancomycin resistant. Au-NM antibacterial activity was enhanced also by binding to nonantibiotic molecules such as amino-substituted pyrimidines [80] and citrate, which together with light energy, induced ROS production and mutations used in therapy against cancer cells [81]. Another example of an antibacterial approach, adopted from cancer treatments, is the $\mathrm{Au}-\mathrm{NM}$ bound to $\mathrm{Fe}_{3} \mathrm{O}_{4}$ and activated by photothermal treatment [82]. The stability of Au-NM compared with that of other metal NM, such as platinum (Pt) [83], render them in many cases the preferred antibacterial NM.

Most of the knowledge about Pt NM comes from cancer research where it was shown in mammalian cells that $\mathrm{Pt}$ NM diffuse through membranes and induce DNA damage, accumulation of cells at the S-phase of the cell cycle, and apoptosis [84]. Recently, however, the toxicity of Pt NM to bacteria was also demonstrated and found to be sizedependent. Pt NM particles of 1-3 nm size were bactericidal to $P$. aeruginosa cells, whereas those of $4-21 \mathrm{~nm}$ size exhibited bacteriocompatible properties [85].

Another recent study showed that when Pt and Au, each alone nontoxic to bacteria, are combined in a bimetallic setting, they have a strong bactericidal effect [86]. Interestingly, in contrast to other NM this effect was ROS-independent, cell death resulting according to the authors from membrane damage and a severe elevation of ATP [86].

3.5. Copper Oxide. Although copper oxide $(\mathrm{CuO})$ nanoparticles have been shown to be effective against various bacterial pathogens, their antibacterial efficacy is somewhat inferior to that of $\mathrm{Ag}$ or $\mathrm{ZnO}$. Hence, a comparatively higher concentration of nanoparticles is needed to achieve the same results [87]. Moreover, $\mathrm{CuO}$ nanoparticle activity varies greatly depending on the challenged bacterial species. Nonetheless, as $\mathrm{Cu}$ is much less expensive than other nanosized metal materials, it can be utilized for efficacy enhancement in the form of nanocomposites.

Copper oxide $(\mathrm{CuO}) \mathrm{NM}$, like the other metallic nanoparticles, exert their antibacterial activity $[88,89]$ by membrane disruption and ROS production [7]. In general, Co NM are less potent than Ag-NM, although in some cases the reverse is true. For example, E. coli and S. aureus were more sensitive to silver, whereas $B$. subtilis and $B$. anthracis were more sensitive to $\mathrm{Cu} \mathrm{NM}[90,91]$. A comparison of $\mathrm{CuO}$ $\mathrm{NM}$ with metallic MN other than Ag-NM showed that they have the strongest antibacterial activity $[9,92]$. A possible explanation for these observations is that bacteria, such as $B$. subtilis, with cell walls rich in amine and carboxyl groups, bind more strongly to $\mathrm{CuO}$ and thus are more sensitive to it $[7,11,15]$. Thus it seems that in special cases it would be beneficial to use the $\mathrm{CuO}$ NM instead of others, including silver.

3.6. Magnesium Oxide. Nano-magnesium oxides ( $\mathrm{MgO})$ are additional antibacterial metal oxide NM that have been shown to exhibit bactericidal activity. Nano- $\mathrm{MgO}$ particles were reported to exhibit efficient antimicrobial activity against bacteria (both Gram-positive and Gram-negative), spores, and viruses. Compared to other metal nanoparticles, 
nano-MgO has the advantage that it can be prepared from available and economical precursors.

Magnesium $(\mathrm{Mg})$ can be used in various $\mathrm{NM}$ in the form of $\mathrm{MgO}$ or $\mathrm{MgX}_{2}$ (e.g., $\mathrm{MgF}_{2}$ ) [7, 93]. In addition to inducing ROS, Mg-containing NM may directly inhibit essential enzymes of the bacteria [15]. $\mathrm{MgF}_{2} \mathrm{NM}$ were found to prevent biofilm formation of E. coli and S. aureus [94, 95].

3.7. Superparamagnetic Iron Oxide. Superparamagnetic iron oxide (SPION) represents a relatively new approach using magnetic particles that cause local hyperthermia in the presence of a magnetic field [96] or, alternatively, they can be coated by other NM such as Ag and Au and their magnetic effect can be utilized to penetrate and destroy biofilms [14, 9799].

3.8. Nitric Oxide. Nitric oxide (NO) NM presents a promising antibacterial compound due to the low risk of possible resistance; that is, NO is involved in multiple mechanisms of antimicrobial activity $[100,101]$. As other metal-based nanoparticles the antibacterial effect is dependent on size and shape [102]; the smaller particles with a high aspect ratio are the most effective. NO is an endogenously produced molecule which is involved in various physiologic functions. Despite all its advantages, its clinical value is limited mainly because it is extremely reactive. However, NO's antimicrobial potential can be exploited upon its encapsulation, controlled release, and focal delivery [103].

Nitric oxide (NO) NM differ from other metal NM by specifically affecting reactive nitrogen species (RNS), rather than ROS. NO NM were found to effectively kill methicillinresistant S. aureus (MRSA) [104] in skin infections [105] and to enhance wound healing of normal and diabetic mice [106]. NO NM are also effective in biofilm eradication of multiple bacterial species [107-109].

3.9. Aluminum Oxide. It is not clear if aluminum oxide $\left(\mathrm{Al}_{2} \mathrm{O}_{3}\right)$ nanoparticles are suitable for antibacterial treatment. First, their bactericidal effect is relatively mild and they work only at high concentrations $[7,110]$ unless in combination with other NM such as Ag [111]. Second and more disturbing is their ability to promote horizontal transfer of multiresistance genes mediated by plasmids across genera [110].

The mechanism of action of aluminum NM, as recently shown for $E$. coli, is by diffusion and accumulation inside the cells, causing pit formation, perforation, and membrane disorganization, leading to cell death [112].

\section{Organic Nanoparticles}

Polymeric nanoparticles kill microorganisms either by releasing antibiotics, antimicrobial peptides, and antimicrobial agents or by contact-killing cationic surfaces such as quaternary ammonium compounds, alkyl pyridiniums, or quaternary phosphonium. Multiple mechanisms of action have been proposed for how these cationic groups are able to disrupt the bacterial cell membrane, with some requiring hydrophobic chains of certain lengths to penetrate and burst the bacterial membrane. It has been shown that high levels of positive charge are capable of conferring antimicrobial properties irrespective of hydrophobic chain length, perhaps by an ion exchange mechanism between the bacterial membrane and the charged surface. The antibacterial effect of polycations is dependent on the ability of multiple charges to attach to and interact with the cell membrane. These findings suggest the possibility of engineering a variety of polymer based positively charged surfaces to create a wide range of contact-killing materials [113].

Organic antibacterial materials are considered less stable in nature mainly at higher temperature when compared with inorganic materials. This may lead to difficulties that arise when designing products meant to be stable and able to withstand harsh process conditions. Therefore inorganic nanosized materials have been more often used as antimicrobial materials. A comprehensive review on antimicrobial polymers has been published [114]. A brief summary of the polymers mentioned in this review is given below.

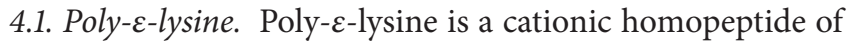
L-lysine which is effective against Gram-positive and Gramnegative bacteria. It also displays activity against spores of $B$. coagulans, B. stearothermophilus, and B. subtilis [115].

4.2. Quaternary Ammonium Compounds. Quaternary ammonium compounds such as benzalkonium chloride, stearalkonium chloride, and cetrimonium chloride are well known disinfectants. Their antimicrobial activity is a function of the $\mathrm{N}$-alkyl chain length and hence lipophilicity. Compounds with alkyl chain length 12-14 of alkyls provide optimum antibacterial activity against Gram-positive bacteria, while alkyls group with 14-16 carbon chains show better activity against Gram-negative bacteria. Initial interaction with bacterial wall results from electrostatic interaction between positively charged moieties of the compound and negatively charged bacterial membranes, followed by the integration of the hydrophobic tail of the compound into the bacterial hydrophobic membrane core, where they denature structural proteins and enzymes.

Antimicrobial polymers with only one biocide end group on polymeric backbone were synthesized by cationic ringopening polymerization of 2-alkyl-1,3-oxazolines, terminating the macromolecule with a cationic surfactant [116]. Quaternary pyridiniums are compounds with a heterocyclic ring containing nitrogen atom. The antibacterial activity is a function of the pyridinium group in the polymer chain. Another family of antimicrobial polymer with aromatic/heterocyclic groups is imidazole derivatives. Imidazole possesses the ability to form hydrogen bond with drugs and proteins while its alkylated form (imidazolium) has the ability to aggregate electrostatically despite losing the hydrogen bond-forming ability of free imidazole. They are chemically stable and biocompatible and show improved biodegradability [117]. Copolymers of N-vinylimidazole and phenacyl methacrylate were synthesized; they display strong antimicrobial activity against various bacteria, fungi, and yeast [118]. Polyethyleneimine (PEI) is a synthetic, nonbiodegradable, 
cationic polymer containing primary, secondary, and tertiary amino functions. PEI was attached to various organic and inorganic, natural and synthetic, macroscopic and nanoscaled, monolithic, and porous surface materials including commercial plastics, textiles, and glass. These immobilized surfaces resulted in inactivation of both waterborne and airborne bacteria and fungi, including pathogenic and antibiotic-resistant strains without any report of emergence of resistance. Cell membrane rupture was reported as a main mechanism for antibacterial action. These surfaces are nontoxic for mammalian cells. $\mathrm{N}$-alkylated PEIs immobilized over different woven textiles (cotton, wool, and polyester) also exhibit strong bactericidal activity against several airborne Gram-positive and Gram-negative bacteria. Mw of PEI poses a significant effect on activity. Substituted PEIs were also used against Candida albicans, presenting a major challenge for the safety of prosthesis deterioration in laryngectomized patients. Polyguanidines and polybiguanides represent an important class of antimicrobial polymers because of their high water solubility, excellent biocidal efficiency, wide antimicrobial spectrum, and nontoxicity. Acrylate monomers with pendant biguanide groups display good antimicrobial action due to electrostatic interaction with cell membranes. A series of different oligomeric guanidines by polycondensation of guanidinium salts and four different diamines under various conditions have been synthesized. The compounds of these series are linear in structure and can be recognized by termination with one guanidine and one amino group (type A), two amino groups (type B), or two guanidine groups (type C), respectively. An average molecular mass of about $800 \mathrm{Da}$ is necessary for efficient antimicrobial activity [119].

4.3. Cationic Quaternary Polyelectrolytes. Most of the known cationic quaternary polyelectrolytes employed as antimicrobial polymers are acrylic or methacrylic derivatives, and a large number of them are synthesized from commercial methacrylic monomers such as 2-(dimethylamino)ethyl methacrylate. These polymers provide wide structural versatility by the alteration of hydrophobicity, molecular weight, surface charge, and other parameters [120].

4.4. N-Halamine Compounds. N-halamine compounds contain one or more nitrogen-halogen covalent bonds that are usually formed by halogenation of imide, amide, or amine groups, which provide stability and slow release free active halogen species into the environment. These oxidizing halogens promote the direct transfer of an active element to the biological target site or through dissociation to free halogen in aqueous media. These reactive free halogens lead to inhibition or inactivation of a microbial cell [121].

4.5. Polysiloxanes. Another important class of polymers is polysiloxanes, the linear polymers of silicon oxide. Sauvet et al. synthesized statistical and block siloxane copolymers containing quaternary ammonium salt groups as a lateral substituent; this research shows high antibacterial activity against both Escherichia coli and Staphylococcus aureus.
However, no difference in activity was observed in block type polymers and statistical copolymers [122].

4.6. Benzoic Acid, Phenol, and p-Hydroxy Benzoate Esters. Benzoic acid, phenol, and p-hydroxy benzoate esters are among the most widely used disinfectants and preservatives. As monomers these compounds have already established their antimicrobial activity. Attempts have been made to incorporate them with some polymer backbone to synthesize new antimicrobial polymers with enhanced activity. In a comparative study of $\mathrm{p}$-hydroxyphenyl acrylate, allyl phydroxyphenyl acetate, and p-2-propen oxyphenol for their antimicrobial action against both bacteria and fungi, phydroxyphenyl acrylate has been shown to be the most effective [123]. The stereo electronic effect of the phenyl group is a major contributing factor for antimicrobial activity of p-hydroxyphenyl acrylate derivatives. Compounds with acryl or acryloxy groups bound to the phenyl moiety exhibit better antimicrobial activities than aliphatic acrylates and hexyl acrylate [124]. Another important compound of this class is "benzaldehyde," known for its bactericidal, fungicidal, and algaecidal activities. Benzaldehyde containing methyl methacrylate polymers have been synthesized and tested against Bacillus macroides, Pseudomonas aeruginosa, and Dunaliella tertiolecta. Polymers show fivefold inhibition of algae growth compared to acid-glass control surfaces [125].

4.7. Quaternary Phosphonium or Sulfonium Groups. Polymers possessing quaternary phosphonium or sulfonium groups display mechanisms similar to the quaternary ammonium group containing compounds. In terms of antimicrobial activity, phosphonium containing polycationic biocides are more effective than quaternary ammonium salt polymers. Studies carried out on water soluble thermosensitive copolymer NIPAAm and methacryloyloxyethyl trialkyl phosphonium chlorides indicate that the antimicrobial activity increases with an increase in length of the alkyl chain and phosphonium units in the polymer [126].

4.8. Triclosan. One of the most widely used antimicrobial agents is triclosan. In experiments solutions of triclosan were mixed with water-based styrene-acrylate emulsion; the resultant systems were tested against Enterococcus faecalis. Based upon an agar diffusion test, it was demonstrated that the release of triclosan depends on the solvent, being almost inexistent or very slow with water and very rapid with n-heptane [127]. In another experiment triclosan was incorporated in water-dispersible PVA nanoparticles that shows greater antibacterial activity towards Corynebacterium than the organic/aqueous solutions of triclosan [128].

4.9. 5-Chloro-8-hydroxy-quinoline. Acrylate polymers containing 5-chloro-8-hydroxy-quinoline were studied at physiological, acidic, and basic $\mathrm{pH}$ for their hydrolytic behavior. Hydrolysis occurs by autocatalysis and is potentiated by $\mathrm{pH}$, temperature, and the content of hydrophilic polymers. Copolymerization of this polymer with $\mathrm{N}$-vinyl pyrrolidone reduces the rate of hydrolysis due to steric hindrance [129]. 
4.10. Peptides. Various peptides were synthesized via ring-opening polymerization of $\alpha$-amino acid $\mathrm{N}$-carboxyanhydride (NCA) monomers using lysine $(\mathrm{K})$ as the hydrophilic amino acid and alanine $(\mathrm{A})$, phenylalanine $(\mathrm{F})$, and leucine (L) as hydrophobic amino acids. They varied the content of hydrophobic from 0 to $100 \%$ and obtained five series of copeptides (i.e., $\mathrm{P}(\mathrm{KA}), \mathrm{P}(\mathrm{KL}), \mathrm{P}(\mathrm{KF}), \mathrm{P}(\mathrm{KAL})$, and $\mathrm{P}(\mathrm{KFL}))$. MIC values determination against Escherichia coli, Pseudomonas aeruginosa, Serratia marcescens, and Candida albicans demonstrate that the $\mathrm{P}(\mathrm{KF})$ copeptides have broader antimicrobial activity and are more efficient than the $\mathrm{P}(\mathrm{KL})$ and $\mathrm{P}(\mathrm{KA})$ series. Similarly, the $\mathrm{P}(\mathrm{KFL})$ series is more effective than the $\mathrm{P}(\mathrm{KAL})$ series [130].

4.11. Organometallic Polymers. Organometallic polymers contain metals either in the backbone chain or in the pendant group, bonded to the polymer by $\Pi$-bonds to carbon, coordination bonds to elements containing free electron pairs, or $\rho / \Pi$-bonds to other elements. Carraher et al. synthesized organotin polyamine ethers containing acyclovir in their backbone. Many such compounds were synthesized by varying alkyl group (methyl, ethyl, butyl, octyl, cyclohexyl, and phenyl) and tested against herpes simplex virus-1 (HSV-1) and Varicella zoster virus (VZV). These polymers present a good inhibition of both RNA and DNA viruses [131].

4.12. Polymeric Nanosized Antimicrobials. Polymeric nanosized antimicrobial agents are known to have long-term antimicrobial activity: they are nonvolatile and chemically stable, can bind to the surface of interest, and hardly permeate through biological membranes such as the skin [132]. Distinctively, polycationic antimicrobials have a high surface density of active groups which might result in increased antimicrobial activity. Quaternary ammonium compounds have a broad spectrum of antimicrobial activity against both Gram-positive and Gram-negative bacteria. Polyamines that have been reported as being highly effective antimicrobial nanoparticles are quaternary ammonium polyethylenimines (QPEI), which have a broad range of bacterial targets when incorporated in various polymeric matrixes [133, 134]. Similarly, lipid nanoparticles are attractive for their biocompatibility, versatility, and their ability to target biofilm infections.

4.13. Polycationic Nanoparticles. QPEI are unique among other NM in their ability to induce intracellular death signal. This yet unidentified signal causes death of cells in layers of biofilm that are not in direct contact with the nanoparticles [21]. This observation, that NM might induce bacterial programmed cell death, is extremely interesting. Such signals, if identified, may theoretically be used to enhance the NM's activity and efficacy. Moreover, such signals may efficiently be the answer to one of the principal shortfalls of antibiotics, being their poor ability to penetrate biofilms. The field of programmed cell death (PCD) in bacteria is still enigmatic and controversial, yet there is growing evidence that PCD plays an important role in the life cycle of bacterial cultures and moreover that it is regulated by secreted signals.
4.14. Chitosan. Chitosan ( $\mathrm{Ch}$ ) nanoparticles have also been shown to have broad spectrum antibacterial, antiviral, and antifungal activity. Lately, Chitosan-hydroxycinnamic acid conjugates were introduced with high bactericidal activity [135]. The widespread applications of $\mathrm{Ch}$ are primarily based on their biocompatibility, nontoxic nature, antibacterial properties, low immunogenicity, and the ability to act as an absorption enhancer. Chitosan NM are nanoparticles obtained by $\mathrm{N}$-deacetylation of the $\mathrm{N}$-acetylglucosamine polymer chitin commonly found in the exoskeleton of insects. Chitosan nanoparticles display considerable antibacterial activity [136], which depends on several factors, including $\mathrm{pH}$ and solvent $[137,138]$. Interestingly, chitosan reduced the activity of metal NM such as $\mathrm{Zn}$ [137]. Thus it appears that it should not be combined with metal NM but possibly with antibiotics [139].

The antibacterial mode of action of chitosan is not fully understood [11]. A recent comprehensive study of the effect of chitosan on $B$. cenocepacia indicated that many membranerelated functions were affected including respiration and resistance nodulation cell division (RND), drug efflux system, and transport. This is possibly due to interaction of lipopolysaccharides with chitosan, resulting in the destabilization of membrane protein sand membrane lysis, leading to cell death [140].

In summary, it seems that regarding NM's mode of action a lot is still obscure. Several NM killing pathways are still elusive and need to be discovered. The effects of NM's treatment combinations are still poorly understood. Last, the involvement of, yet controversial, bacterial intrinsic pathways of programmed cell death in NM's dependent killing needs to be further clarified.

\section{Synthesis/Preparation Methods}

Nano-antimicrobial materials can be synthesized by variety of different methods. Recent work showed that the mechanism of action and activity of materials may influence subsequent antimicrobial effect. Table 1 represents synthesis/preparation method for selected antimicrobial NM with material description and antimicrobial activity.

\section{Biocompatibility of Nanomaterials}

The biocompatibility of nanomaterials must be explored prior to their use in biomedical applications such as drug delivery, gene delivery, biosensors, or the treatment of wound infections. In such applications, the NM come in direct contact with tissues and cells, where they can cause beneficial or destructive effects on the body. NM as drugs can gain access to the body by inhalation, oral ingestion, intravenous injection, and contact with the skin [113]. The effect of NP on various body tissues is not known, and the interaction of NM with cells and tissues is poorly understood.

The toxicity of NP can be assessed by a number of in vitro and in vivo methods (Scheme 2 ). The in vitro research is conducted on cell cultures. Cell culture assays are used as a prescreening tool to understand the biological effects of 


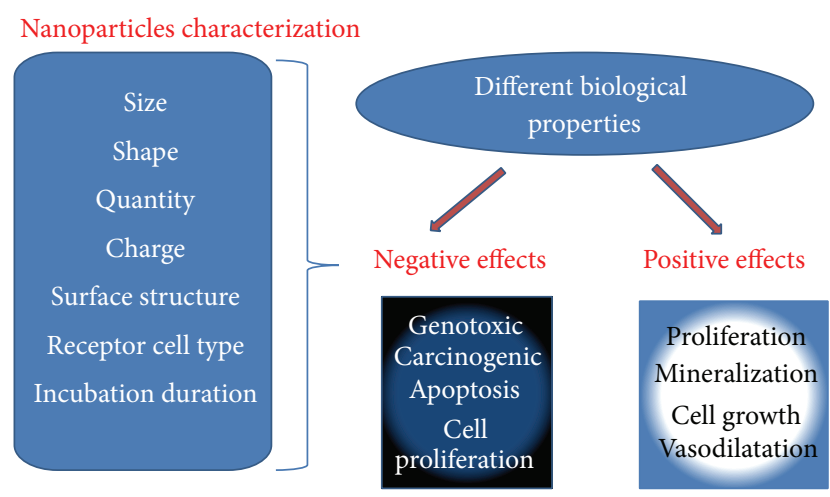

Scheme 2: NM biocompatibility from in vitro studies. The biological activity of different organic and inorganic NM varies from negative to positive effects in different systems of in vitro cell lines. This activity depends on various factors such as size, electrical charge, quantity exposed, shape, and surface structure of NM.

NM activity, their toxicity, and mechanism of action. A few inorganic and many synthesized polymeric NM have been shown to have different levels of biocompatibility. Herein, several such NM and their effective roles are discussed.

\section{Inorganic Nanoparticles}

Metal NM have in several studies been shown to be cytotoxic $[114,141]$, genotoxic [142], and potentially carcinogenic [143] and to induce apoptosis and inhibit cell proliferation [144]. Some studies found that NM toxicity depends on particle size and charges. Negatively charged $10 \mathrm{~nm} \mathrm{SiO}_{2}{ }^{-}$have a strong impact on cell viability and genotoxic effects, but the largest particles $(100 \mathrm{~nm})$ do not affect cell activity.

Ag-NP and Au-NM showed the best results in terms of toxicity and were defined as nontoxic for human cells [145].

Pure $\mathrm{Ti}$ and $\mathrm{TiO}_{2}$ are extensively used for dental and orthopedic implants owing to their high mechanical properties and biocompatibility. The biocompatibility of $\mathrm{Ti}$ is dependent on the characteristics of vertically aligned $\mathrm{TiO}_{2}$ nanoporous surfaces [146]. Titanium foils are covered by the vertically aligned nanoporous surface of $\mathrm{TiO}_{2}$, and the $\mathrm{TiO}_{2}$ nanoporous surface enhances the proliferation and mineralization of osteoblasts and increases mobility, as well as vasodilation of endothelial cells [147]. Giavaresi et al. found that nanostructured $\mathrm{TiO}_{2}$ coating had a positive effect on cell proliferation and activity [148]. Another study reported that the growth rate of osteoblast cells increased threeto fourfold in response to treatment with $\mathrm{TiO}_{2}$ nanotubes [149]. As mentioned above, some of the inorganic NM have toxic effects on both microbial and animal cells, and their relative biocompatibility and toxicity are dose- and celltype dependent. Furthermore, with modification of their structure, effective levels of biocompatible properties have been observed in metals such as Ag [150].

A number of studies have reported the nontoxic and biocompatible behavior of SPION nanoparticles in different human and animal cells. Jian et al. investigated the in vivo behavior of SPION in rat liver and concluded that it did not influence liver function or induce oxidative stress [151]. Furthermore, Sun et al. showed good biocompatibility of sodium oleate-coated iron oxide NM [152].

Although the results of the cell culture studies are promising, the in vitro assays should be confirmed by in vivo studies conducted in animal models before NM applications are available for human use. The relatively small number of animal investigations designed to determine the toxicity of NM of different sizes and shapes, as well as dose-dependence, has not allowed conclusions to be drawn as to whether NM as potential antimicrobial agents are safe for humans. Therefore, NM toxicity studies are necessary to determine risk assessment.

Using $\mathrm{ZnO}$ nanowires (NWs) in Hela and L929 culture cells, Li et al. reported that Hela cells showed full biocompatibility with $\mathrm{ZnO}$ nanowires (NWs) at all concentrations. However, the multiplication capacity of L929 cells was good at lower NW levels whereas cell viability was reduced by $50 \%$ at higher levels of $\mathrm{ZnO} \mathrm{NW}$ [153].

The cytotoxic behavior of nanomaterials is somewhat different in higher animal cells but still exists. Some NM, such as $\mathrm{Ag}, \mathrm{ZnO}$, and $\mathrm{TiO}_{2}$, show moderate to high levels of cytotoxicity against a variety of animal cells. In addition, some $\mathrm{NM}$ including $\mathrm{SiO}_{2}, \mathrm{Au}, \mathrm{Fe}_{2} \mathrm{O}_{3}$, and $\mathrm{TiO}_{2}$ have also shown a very good level of biocompatible properties. Even cytotoxic NM have been converted into biocompatible materials through slight variations in their surface structure. Therefore, it may be concluded that NM possess a broad level of biological properties that are highly dependent upon their size, structure, quantity, and receptor cell type. However, further studies are still required to identify additional reasons for their behavior.

Moreover, the in vivo toxicological effects of NM are much more severe than their in vitro effects. Nanomaterials that penetrate the body through the skin, by respiration or by inhalation, directly affect major body organs including the lungs, heart, and brain.

The toxicity of Au-NM (4-5 nm) after rat inhalation was represented by a dose-dependent accumulation of gold in lungs, inflammation, and an increased number of macrophages [154]. de Jong et al. determined the sizedependent organ distribution of Au-NM (10, 50, 100, and $250 \mathrm{~nm}$ ) after intravenous administration to rats. Their results showed that $10 \mathrm{~nm}$ Au-NM was the amount most widespread in the various organ systems, including brain, heart, kidneys, lungs, testis, and thymus. Oral toxicity, eye irritation, corrosion, and dermal toxicity of colloidal Ag-NM were conducted in mice and guinea pig models [155]. Their findings suggest that Ag-NM could be relatively safe if administered for short periods of time.

However, the exact toxicological mechanism of NM and the level of hazard they pose are unknown. The toxic effects of NM may be attributed to various factors. However, generation of ROS is considered the main determinant for both their in vitro and in vivo cytotoxicity. ROS is physiologically essential but potentially destructive to eukaryotic cells. Several cellular events are governed by lower levels of ROS, but when they increase beyond certain limits they cause severe oxidative stress, resulting in cell death via oxidation 


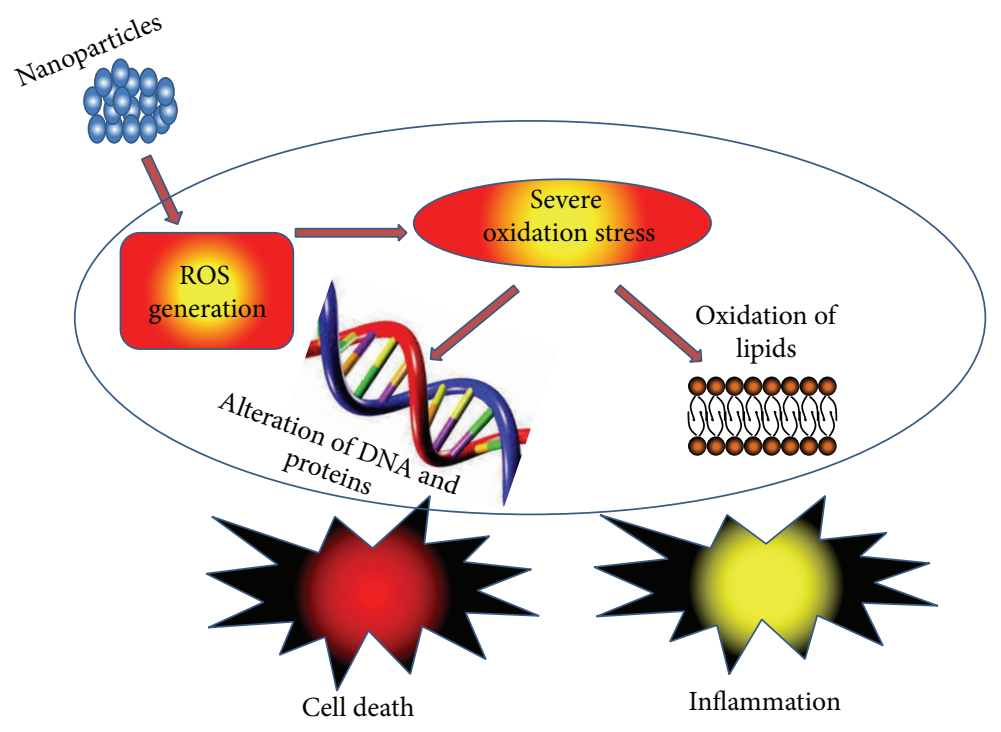

SCHEME 3: Toxicological mechanisms of NM to eukaryotic cells. Nanoparticles induce ROS generation in eukaryotic cells; these radicals cause severe oxidation stress in the cells, affecting membrane lipids and altering the structure of DNA and proteins. This excess radical production induces an inflammatory process that could lead to cell death.

of the lipids and alteration of the DNA and proteins [156158]. ROS generated from $\mathrm{TiO}_{2} \mathrm{NM}$ caused oxidative stress that resulted in early inflammatory responses in mice, rats, and hamsters [159]. Oxidative stress has been shown to be generated by CNT in fish brain and to cause pulmonary inflammation in rats $[160,161]$. The excessive generation of ROS has also been reported to damage mitochondrial DNA $[162,163]$. The toxic effects generated by ROS are not confined to particular cells or organs but also affect various body systems and functions, including the central nervous system (CNS), respiratory system, and cardiac conduction $[164,165]$.

\section{Organic Nanoparticles}

Incorporation of QPEI-based nanoparticles at low concentrations did not change the biocompatibility results when compared with the commercial dental restorative materials. This effect was tested by cell viability (XTT) and TNF $\alpha$ secretion of monocytes challenged by these NM [166]. This biocompatibility of QPEI was also shown when the nanoparticles were incorporated in endodontic sealers [167] and soft liner materials.

It may be concluded that most NM have both cytotoxic and compatible properties. Moreover, these properties are highly dependent on various parameters, including the size of the NM, dose, cell type, and incubation duration. The properties can be customized by slightly modifying the surface or charge properties of the nanomaterial. However, a great deal of intensive research is still required to determine the basis for the various NM properties.

Despite the numerous advantages that antibacterial NM offer, they also have some imperative shortcomings. Nanomaterials may be toxic to human cells and tissue, causing oxidative stress, disturbing enzymes activity, and causing membrane and DNA damage, all of which lead to cell death (Scheme 3). Nonetheless, recent studies show that NM have the potential to be efficient antibacterial agents, provided their main disadvantage, toxicity, will be addressed.

\section{Summary}

Bacterial strains resistant to the antibiotics now in use have become a serious public health problem that increases the need to develop new bactericidal materials. Consequently, there is a strong demand for developing novel strategies and new materials that can cope with these serious issues. The emergence of nanotechnology has created many new antimicrobial options. The small size of the NM is very suitable for carrying out antimicrobial biological operations. Metal, organic, and additional nanoparticle types have shown tremendous potential as bactericidal and fungicidal elements, demonstrating their potential as efficient antibiotic reagents in wound care and related medical issues. The efficacy of these nanoparticles varies with their characteristics including size, shape, and concentration. Moreover, the atomic abundance on the particles' surface plays a role in the properties of such materials. As the size of the particle decreases, the percentage of atoms on the surface increases relative to the total atoms of material, amplifying the activity. Various NM display antimicrobial activity against numerous pathogenic viral and bacterial species. Likewise NM have shown sufficient biocompatibility when incorporated in scaffold materials. Nanomaterials today are a promising platform for alternative measures to control bacterial infections.

Antimicrobial NM offers a wide range of classes and applications. These antimicrobial NM offer prolonged antimicrobial activity with negligible toxicity, compared with small molecular antimicrobial agents that display shortterm activity and environmental toxicity. The emergence 
of resistant species is one of the major problems with small molecular antibiotics due to their specific targets of action, whereas antimicrobial NM physically destroys cell membranes of the organism which prevent development of drug-resistance microbes. Due to these advantages provided by antimicrobial NM, efforts have been made to apply these NM as contact surfaces for medical devices, fibers, and textiles, rendering them antimicrobial. Advanced quality research, dedicated efforts, successful application, and commercialization of antimicrobial NM will help fulfill the need to improve the quality of life.

\section{Conflict of Interests}

The authors declare that there is no conflict of interests regarding the publication of this paper.

\section{References}

[1] M. E. Davey and G. A. O’Toole, "Microbial biofilms: from ecology to molecular genetics," Microbiology and Molecular Biology Reviews, vol. 64, no. 4, pp. 847-867, 2000.

[2] L. Hall-Stoodley, J. W. Costerton, and P. Stoodley, "Bacterial biofilms: from the natural environment to infectious diseases," Nature Reviews Microbiology, vol. 2, no. 2, pp. 95-108, 2004.

[3] P. Watnick and R. Kolter, "Biofilm, city of microbes," Journal of Bacteriology, vol. 182, no. 10, pp. 2675-2679, 2000.

[4] R. M. Donlan, "Role of biofilms antimicrobial resistance," ASAIO Journal, vol. 46, no. 6, pp. S47-S52, 2000.

[5] J. T. Seil and T. J. Webster, "Antimicrobial applications of nanotechnology: methods and literature," International Journal of Nanomedicine, vol. 7, pp. 2767-2781, 2012.

[6] A.-P. Magiorakos, A. Srinivasan, R. B. Carey et al., "Multidrugresistant, extensively drug-resistant and pandrug-resistant bacteria: an international expert proposal for interim standard definitions for acquired resistance," Clinical Microbiology and Infection, vol. 18, no. 3, pp. 268-281, 2012.

[7] R. Y. Pelgrift and A. J. Friedman, "Nanotechnology as a therapeutic tool to combat microbial resistance," Advanced Drug Delivery Reviews, vol. 65, no. 13-14, pp. 1803-1815, 2013.

[8] L. Zhang, D. Pornpattananangkul, C.-M. J. Hu, and C.-M. Huang, "Development of nanoparticles for antimicrobial drug delivery," Current Medicinal Chemistry, vol. 17, no. 6, pp. 585$594,2010$.

[9] Y.-W. Baek and Y.-J. An, "Microbial toxicity of metal oxide nanoparticles $\left(\mathrm{CuO}, \mathrm{NiO}, \mathrm{ZnO}\right.$, and $\left.\mathrm{Sb}_{2} \mathrm{O}_{3}\right)$ to Escherichia coli, Bacillus subtilis, and Streptococcus aureus," The Science of the Total Environment, vol. 409, no. 8, pp. 1603-1608, 2011.

[10] D. Nath and P. Banerjee, "Green nanotechnology-a new hope for medical biology," Environmental Toxicology and Pharmacology, vol. 36, no. 3, pp. 997-1014, 2013.

[11] A. J. Huh and Y. J. Kwon, “Nanoantibiotics': a new paradigm for treating infectious diseases using nanomaterials in the antibiotics resistant era," Journal of Controlled Release, vol. 156, no. 2, pp. 128-145, 2011.

[12] M. A. Gatoo, S. Naseem, M. Y. Arfat, A. M. Dar, K. Qasim, and S. Zubair, "Physicochemical properties of nanomaterials: implication in associated toxic manifestations," BioMed Research International, vol. 2014, Article ID 498420, 8 pages, 2014.
[13] A. A. Ashkarran, M. Ghavami, H. Aghaverdi, P. Stroeve, and M. Mahmoudi, "Bacterial effects and protein corona evaluations: crucial ignored factors in the prediction of bio-efficacy of various forms of silver nanoparticles," Chemical Research in Toxicology, vol. 25, no. 6, pp. 1231-1242, 2012.

[14] M. J. Hajipour, K. M. Fromm, A. A. Ashkarran et al., "Antibacterial properties of nanoparticles," Trends in Biotechnology, vol. 30, no. 10, pp. 499-511, 2012.

[15] K. Blecher, A. Nasir, and A. Friedman, "The growing role of nanotechnology in combating infectious disease," Virulence, vol. 2, no. 5, pp. 395-401, 2011.

[16] C. Nathan and A. Cunningham-Bussel, "Beyond oxidative stress: an immunologist's guide to reactive oxygen species," Nature Reviews Immunology, vol. 13, no. 5, pp. 349-361, 2013.

[17] X. Pan, J. E. Redding, P. A. Wiley, L. Wen, J. S. McConnell, and B. Zhang, "Mutagenicity evaluation of metal oxide nanoparticles by the bacterial reverse mutation assay," Chemosphere, vol. 79, no. 1, pp. 113-116, 2010.

[18] S. Wang, R. Lawson, P. C. Ray, and H. Yu, “Toxic effects of gold nanoparticles on Salmonella typhimurium bacteria," Toxicology and Industrial Health, vol. 27, no. 6, pp. 547-554, 2011.

[19] V. Matěejka and J. Tokarský, "Photocatalytical nanocomposites: a review," Journal of Nanoscience and Nanotechnology, vol. 14, no. 2, pp. 1597-1616, 2014.

[20] P.-C. Maness, S. Smolinski, D. M. Blake, Z. Huang, E. J. Wolfrum, and W. A. Jacoby, "Bactericidal activity of photocatalytic $\mathrm{TiO}_{2}$ reaction: toward an understanding of its killing mechanism," Applied and Environmental Microbiology, vol. 65, no. 9, pp. 4094-4098, 1999.

[21] N. Beyth, I. Yudovin-Farber, M. Perez-Davidi, A. J. Domb, and E. I. Weiss, "Polyethyleneimine nanoparticles incorporated into resin composite cause cell death and trigger biofilm stress in vivo," Proceedings of the National Academy of Sciences of the United States of America, vol. 107, no. 51, pp. 22038-22043, 2010.

[22] L. Loomba and T. Scarabelli, "Metallic nanoparticles and their medicinal potential. Part I. Gold and silver colloids," Therapeutic Delivery, vol. 4, no. 7, pp. 859-873, 2013.

[23] M. Rai, A. Yadav, and A. Gade, "Silver nanoparticles as a new generation of antimicrobials," Biotechnology Advances, vol. 27, no. 1, pp. 76-83, 2009.

[24] A. Avalos, A. I. Haza, D. Mateo, and P. Morales, "Interactions of manufactured silver nanoparticles of different sizes with normal human dermal fibroblasts," International Wound Journal, 2014.

[25] C. Elliott, "The effects of silver dressings on hronic and burns wound healing," British Journal of Nursing, vol. 19, no. 15, pp. S32-S36, 2010.

[26] N. P. Aditya, P. G. Vathsala, V. Vieira, R. S. R. Murthy, and E. B. Souto, "Advances in nanomedicines for malaria treatment," Advances in Colloid and Interface Science, vol. 201-202, pp. 1-17, 2013.

[27] S. Poulose, T. Panda, P. P. Nair, and T. Théodore, "Biosynthesis of silver nanoparticles," Journal of Nanoscience and Nanotechnology, vol. 14, no. 2, pp. 2038-2049, 2014.

[28] A. Panáček, L. Kvítek, R. Prucek et al., "Silver colloid nanoparticles: synthesis, characterization, and their antibacterial activity," The Journal of Physical Chemistry B, vol. 110, no. 33, pp. 1624816253, 2006.

[29] I. Chopra, "The increasing use of silver-based products as antimicrobial agents: a useful development or a cause for concern?" The Journal of Antimicrobial Chemotherapy, vol. 59, no. 4, pp. 587-590, 2007. 
[30] S. de Simone, A. L. Gallo, F. Paladini, A. Sannino, and M. Pollini, "Development of silver nano-coatings on silk sutures as a novel approach against surgical infections," Journal of Materials Science: Materials in Medicine, vol. 25, no. 9, pp. 22052214, 2014.

[31] J. G. Leid, A. J. Ditto, A. Knapp et al., "In vitro antimicrobial studies of silver carbene complexes: activity of free and nanoparticle carbene formulations against clinical isolates of pathogenic bacteria," The Journal of Antimicrobial Chemotherapy, vol. 67, no. 1, pp. 138-148, 2012.

[32] S. Chernousova and M. Epple, "Silver as antibacterial agent: ion, nanoparticle, and metal," Angewandte Chemie-International Edition, vol. 52, no. 6, pp. 1636-1653, 2013.

[33] S. Silver, "Bacterial silver resistance: molecular biology and uses and misuses of silver compounds," FEMS Microbiology Reviews, vol. 27, no. 2-3, pp. 341-353, 2003.

[34] A. Ugur and Ö. Ceylan, "Occurrence of resistance to antibiotics, metals, and plasmids in clinical strains of Staphylococcus spp.," Archives of Medical Research, vol. 34, no. 2, pp. 130-136, 2003.

[35] Z. Sheng and Y. Liu, "Effects of silver nanoparticles on wastewater biofilms," Water Research, vol. 45, no. 18, pp. 6039-6050, 2011.

[36] P. L. Drake and K. J. Hazelwood, "Exposure-related health effects of silver and silver compounds: a review," The Annals of Occupational Hygiene, vol. 49, no. 7, pp. 575-585, 2005.

[37] T. M. Tolaymat, A. M. El Badawy, A. Genaidy, K. G. Scheckel, T. P. Luxton, and M. Suidan, "An evidence-based environmental perspective of manufactured silver nanoparticle in syntheses and applications: a systematic review and critical appraisal of peer-reviewed scientific papers," Science of the Total Environment, vol. 408, no. 5, pp. 999-1006, 2010.

[38] T. Bartłomiejczyk, A. Lankoff, M. Kruszewski, and I. Szumiel, "Silver nanoparticles-allies or adversaries?" Annals of Agricultural and Environmental Medicine, vol. 20, no. 1, pp. 48-54, 2013.

[39] A. Majdalawieh, M. C. Kanan, O. El-Kadri, and S. M. Kanan, "Recent advances in gold and silver nanoparticles: synthesis and applications," Journal of Nanoscience and Nanotechnology, vol. 14, no. 7, pp. 4757-4780, 2014.

[40] I. Sondi and B. Salopek-Sondi, "Silver nanoparticles as antimicrobial agent: a case study on E. coli as a model for Gramnegative bacteria," Journal of Colloid and Interface Science, vol. 275, no. 1, pp. 177-182, 2004.

[41] O. Choi, K. K. Deng, N.-J. Kim, L. Ross Jr., R. Y. Surampalli, and $\mathrm{Z} . \mathrm{Hu}$, "The inhibitory effects of silver nanoparticles, silver ions, and silver chloride colloids on microbial growth," Water Research, vol. 42, no. 12, pp. 3066-3074, 2008.

[42] D. Ashok Kumar, V. Palanichamy, and S. M. Roopan, "Photocatalytic action of $\mathrm{AgCl}$ nanoparticles and its antibacterial activity," Journal of Photochemistry and Photobiology B: Biology, vol. 138, pp. 302-306, 2014.

[43] S. Ninganagouda, V. Rathod, D. Singh et al., "Growth kinetics and mechanistic action of reactive oxygen species released by silver nanoparticles from Aspergillus niger on Escherichia coli," BioMed Research International, vol. 2014, Article ID 753419, 9 pages, 2014.

[44] C. Carlson, S. M. Hussein, A. M. Schrand et al., "Unique cellular interaction of silver nanoparticles: size-dependent generation of reactive oxygen species," Journal of Physical Chemistry B, vol. 112, no. 43, pp. 13608-13619, 2008.
[45] M. J. Piao, K. A. Kang, I. K. Lee et al., "Silver nanoparticles induce oxidative cell damage in human liver cells through inhibition of reduced glutathione and induction of mitochondriainvolved apoptosis," Toxicology Letters, vol. 201, no. 1, pp. 92100, 2011.

[46] E. M. Luther, Y. Koehler, J. Diendorf, M. Epple, and R. Dringen, "Accumulation of silver nanoparticles by cultured primary brain astrocytes," Nanotechnology, vol. 22, no. 37, Article ID 375101, 2011.

[47] C. Greulich, J. Diendorf, J. Gessmann et al., "Cell type-specific responses of peripheral blood mononuclear cells to silver nanoparticles," Acta Biomaterialia, vol. 7, no. 9, pp. 3505-3514, 2011.

[48] C. Khurana, A. K. Vala, N. Andhariya, O. P. Pandey, and B. Chudasama, "Antibacterial activities of silver nanoparticles and antibiotic-adsorbed silver nanoparticles against biorecycling microbes," Environmental Science: Processes \& Impacts, vol. 16, no. 9, pp. 2191-2198, 2014.

[49] A. R. Shahverdi, A. Fakhimi, H. R. Shahverdi, and S. Minaian, "Synthesis and effect of silver nanoparticles on the antibacterial activity of different antibiotics against Staphylococcus aureus and Escherichia coli," Nanomedicine: Nanotechnology, Biology, and Medicine, vol. 3, no. 2, pp. 168-171, 2007.

[50] A. M. Allahverdiyev, E. S. Abamor, M. Bagirova, and M. Rafailovich, "Antimicrobial effects of $\mathrm{TiO}_{2}$ and $\mathrm{Ag}_{2} \mathrm{O}$ nanoparticles against drug-resistant bacteria and leishmania parasites," Future Microbiology, vol. 6, no. 8, pp. 933-940, 2011.

[51] C. Wei, W.-Y. Lin, Z. Zalnal et al., "Bactericidal activity of $\mathrm{TiO}_{2}$ photocatalyst in aqueous media: toward a solar-assisted water disinfection system," Environmental Science and Technology, vol. 28, no. 5, pp. 934-938, 1994.

[52] A. S. Brady-Estévez, S. Kang, and M. Elimelech, "A singlewalled-carbon-nanotube filter for removal of viral and bacterial pathogens," Small, vol. 4, no. 4, pp. 481-484, 2008.

[53] L. Zan, W. Fa, T. Peng, and Z.-K. Gong, "Photocatalysis effect of nanometer $\mathrm{TiO}_{2}$ and $\mathrm{TiO}_{2}$-coated ceramic plate on Hepatitis B virus," Journal of Photochemistry and Photobiology B: Biology, vol. 86, no. 2, pp. 165-169, 2007.

[54] A. M. Allahverdiyev, E. S. Abamor, M. Bagirova et al., "Investigation of antileishmanial activities of Tio $@$ @Ag nanoparticles on biological properties of L. tropica and L. infantum parasites, in vitro," Experimental Parasitology, vol. 135, no. 1, pp. 55-63, 2013.

[55] D. B. Hamal, J. A. Haggstrom, G. L. Marchin, M. A. Ikenberry, K. Hohn, and K. J. Klabunde, "A multifunctional biocide/sporocide and photocatalyst based on titanium dioxide $\left(\mathrm{TiO}_{2}\right)$ codoped with silver, carbon, and sulfur," Langmuir, vol. 26, no. 4, pp. 2805-2810, 2010.

[56] M. Pratap Reddy, A. Venugopal, and M. Subrahmanyam, "Hydroxyapatite-supported $\mathrm{Ag}-\mathrm{TiO}_{2}$ as Escherichia coli disinfection photocatalyst," Water Research, vol. 41, no. 2, pp. 379386, 2007.

[57] L. G. Devi and B. Nagaraj, "Disinfection of Escherichia coli gram negative bacteria using surface modified $\mathrm{TiO}_{2}$ : optimization of Ag metallization and depiction of charge transfer mechanism," Photochemistry and Photobiology, vol. 90, no. 5, pp. 1089-1098, 2014.

[58] C. Ungureanu, S. Popescu, G. Purcel et al., "Improved antibacterial behavior of titanium surface with torularhodin-polypyrrole film," Materials Science \& Engineering C: Materials for Biological Applications, vol. 42, pp. 726-733, 2014. 
[59] L. Palanikumar, S. N. Ramasamy, and C. Balachandran, "Sizedependent antimicrobial response of zinc oxide nanoparticles," IET Nanobiotechnology, vol. 8, no. 2, pp. 111-117, 2014.

[60] M. A. Ansari, H. M. Khan, A. A. Khan, A. Sultan, and A. Azam, "Characterization of clinical strains of MSSA, MRSA and MRSE isolated from skin and soft tissue infections and the antibacterial activity of $\mathrm{ZnO}$ nanoparticles," World Journal of Microbiology \& Biotechnology, vol. 28, no. 4, pp. 1605-1613, 2012.

[61] E. Malka, I. Perelshtein, A. Lipovsky et al., "Eradication of multidrug resistant bacteria by a novel $\mathrm{Zn}$-doped $\mathrm{CuO}$ nanocomposite," Small, vol. 9, no. 23, pp. 4069-4076, 2013.

[62] Z. Huang, X. Zheng, D. Yan et al., "Toxicological effect of $\mathrm{ZnO}$ nanoparticles based on bacteria," Langmuir, vol. 24, no. 8, pp. 4140-4144, 2008.

[63] S. hakraborti, A. K. Mandal, S. Sarwar, P. Singh, R. Chakraborty, and P. Chakrabarti, "Bactericidal effect of polyethyleneimine capped $\mathrm{ZnO}$ nanoparticles on multiple antibiotic resistant bacteria harboring genes of high-pathogenicity island," Colloids and Surfaces B: Biointerfaces, vol. 121C, pp. 44-53, 2014.

[64] L. S. Reddy, M. M. Nisha, M. Joice, and P. N. Shilpa, "Antimicrobial activity of zinc oxide ( $\mathrm{ZnO}$ ) nanoparticle against Klebsiella pneumoniae," Pharmaceutical Biology, vol. 52, no. 11, pp. 13881397, 2014.

[65] T. Jin, D. Sun, J. Y. Su, H. Zhang, and H.-J. Sue, "Antimicrobial efficacy of zinc oxide quantum dots against Listeria monocytogenes, Salmonella Enteritidis, and Escherichia coli O157:H7," Journal of Food Science, vol. 74, no. 1, pp. M46-M52, 2009.

[66] S. Kasraei, L. Sami, S. Hendi, M.-Y. AliKhani, L. RezaeiSoufi, and Z. Khamverdi, "Antibacterial properties of composite resins incorporating silver and zinc oxide nanoparticles on Streptococcus mutans and Lactobacillus," Restorative Dentistry \& Endodontics, vol. 39, no. 2, pp. 109-114, 2014.

[67] Y. Liu, L. He, A. Mustapha, H. Li, Z. Q. Hu, and M. Lin, "Antibacterial activities of zinc oxide nanoparticles against Escherichia coli O157:H7," Journal of Applied Microbiology, vol. 107, no. 4, pp. 1193-1201, 2009.

[68] K. M. Reddy, K. Feris, J. Bell, D. G. Wingett, C. Hanley, and A. Punnoose, "Selective toxicity of zinc oxide nanoparticles to prokaryotic and eukaryotic systems," Applied Physics Letters, vol. 90, no. 21, Article ID 213902, 2007.

[69] R. Dastjerdi and M. Montazer, "A review on the application of inorganic nano-structured materials in the modification of textiles: focus on anti-microbial properties," Colloids and Surfaces B: Biointerfaces, vol. 79, no. 1, pp. 5-18, 2010.

[70] G. Applerot, J. Lellouche, N. Perkas, Y. Nitzan, A. Gedanken, and E. Banin, "ZnO nanoparticle-coated surfaces inhibit bacterial biofilm formation and increase antibiotic susceptibility," RSC Advances, vol. 2, no. 6, pp. 2314-2321, 2012.

[71] R. Pati, R. K. Mehta, S. Mohanty et al., "Topical application of zinc oxide nanoparticles reduces bacterial skin infection in mice and exhibits antibacterial activity by inducing oxidative stress response and cell membrane disintegration in macrophages," Nanomedicine: Nanotechnology, Biology, and Medicine, vol. 10, no. 6, pp. 1195-1208, 2014.

[72] S. Chatterjee, A. Bandyopadhyay, and K. Sarkar, "Effect of iron oxide and gold nanoparticles on bacterial growth leading towards biological application," Journal of Nanobiotechnology, vol. 9, article 34, 2011.

[73] A. Anghel, A. Grumezescu, M. Chirea et al., "MAPLE fabricated $\mathrm{Fe}_{3} \mathrm{O}_{4} @$ Cinnamomum verum antimicrobial surfaces for improved gastrostomy tubes," Molecules, vol. 19, no. 7, pp. 89818994, 2014.
[74] R. S. Norman, J. W. Stone, A. Gole, C. J. Murphy, and T. L. Sabo-Attwood, "Targeted photothermal lysis of the pathogenic bacteria, pseudomonas aeruginosa, with gold nanorods," Nano Letters, vol. 8, no. 1, pp. 302-306, 2008.

[75] A. N. Brown, K. Smith, T. A. Samuels, J. Lu, S. O. Obare, and M. E. Scott, "Nanoparticles functionalized with ampicillin destroy multiple-antibiotic-resistant isolates of Pseudomonas aeruginosa and Enterobacter aerogenes and methicillin-resistant Staphylococcus aureus," Applied and Environmental Microbiology, vol. 78, no. 8, pp. 2768-2774, 2012.

[76] M. Chamundeeswari, S. S. L. Sobhana, J. P. Jacob et al., "Preparation, characterization and evaluation of a biopolymeric gold nanocomposite with antimicrobial activity," Biotechnology and Applied Biochemistry, vol. 55, no. 1, pp. 29-35, 2010.

[77] M. Varisco, N. Khanna, P. S. Brunetto, and K. M. Fromm, "New antimicrobial and biocompatible implant coating with synergic silver-vancomycin conjugate action," ChemMedChem, vol. 9, no. 6, pp. 1221-1230, 2014.

[78] W. Y. Chen, J. Y. Lin, W. J. Chen, L. Luo, E. Wei-Guang Diau, and Y. C. Chen, "Functional gold nanoclusters as antimicrobial agents for antibiotic-resistant bacteria," Nanomedicine, vol. 5, no. 5, pp. 755-764, 2010.

[79] H.-Y. Chang, J. Cang, P. Roy, H.-T. Chang, Y.-C. Huang, and C.C. Huang, "Synthesis and antimicrobial activity of gold/silvertellurium nanostructures," ACS Applied Materials \& Interfaces, vol. 6, no. 11, pp. 8305-8312, 2014.

[80] Y. Zhao, Y. Tian, Y. Cui, W. Liu, W. Ma, and X. Jiang, "Small molecule-capped gold nanoparticles as potent antibacterial agents that target gram-negative bacteria," Journal of the American Chemical Society, vol. 132, no. 35, pp. 12349-12356, 2010.

[81] V. Raji, J. Kumar, C. S. Rejiya, M. Vibin, V. N. Shenoi, and A. Abraham, "Selective photothermal efficiency of citrate capped gold nanoparticles for destruction of cancer cells," Experimental Cell Research, vol. 317, no. 14, pp. 2052-2058, 2011.

[82] W.-C. Huang, P.-J. Tsai, and Y.-C. Chen, "Multifunctional Fe3O4@Au nanoeggs as photothermal agents for selective killing of nosocomial and antibiotic-resistant bacteria," Small (Weinheim an der Bergstrasse, Germany), vol. 5, no. 1, pp. 51-56, 2009.

[83] B. Hvolbæk, T. V. W. Janssens, B. S. Clausen, H. Falsig, C. H. Christensen, and J. K. Nørskov, "Catalytic activity of $\mathrm{Au}$ nanoparticles," Nano Today, vol. 2, no. 4, pp. 14-18, 2007.

[84] P. V. Asharani, N. Xinyi, M. P. Hande, and S. Valiyaveettil, "DNA damage and p53-mediated growth arrest in human cells treated with platinum nanoparticles," Nanomedicine, vol. 5, no. 1, pp. 51-64, 2010.

[85] J. Gopal, N. Hasan, M. Manikandan, and H. F. Wu, "Bacterial toxicity/compatibility of platinum nanospheres, nanocuboids and nanoflowers," Scientific Reports, vol. 3, article 1260, 2013.

[86] Y. Zhao, C. Ye, W. Liu, R. Chen, and X. Jiang, "Tuning the composition of AuPt bimetallic nanoparticles for antibacterial application," Angewandte Chemie International Edition, vol. 53, no. 31, pp. 8127-8131, 2014.

[87] G. Ren, D. Hu, E. W. C. Cheng, M. A. Vargas-Reus, P. Reip, and R. P. Allaker, "Characterisation of copper oxide nanoparticles for antimicrobial applications," International Journal of Antimicrobial Agents, vol. 33, no. 6, pp. 587-590, 2009.

[88] L. Esteban-Tejeda, F. Malpartida, A. Esteban-Cubillo, C. Pecharromn, and J. S. Moya, "Antibacterial and antifungal activity of a soda-lime glass containing copper nanoparticles," Nanotechnology, vol. 20, no. 50, Article ID 505701, 2009. 
[89] M. Hans, A. Erbe, S. Mathews, Y. Chen, M. Solioz, and F. Mücklich, "Role of copper oxides in contact killing of bacteria," Langmuir, vol. 29, no. 52, pp. 16160-16166, 2013.

[90] P. Pey, M. S. Packiyaraj, H. Nigam, G. S. Agarwal, B. Singh, and M. K. Patra, "Antimicrobial properties of $\mathrm{CuO}$ nanorods and multi-armed nanoparticles against $B$. anthracis vegetative cells and endospores," Beilstein Journal of Nanotechnology, vol. 5, pp. 789-800, 2014.

[91] J. P. Ruparelia, A. K. Chatterjee, S. P. Duttagupta, and S. Mukherji, "Strain specificity in antimicrobial activity of silver and copper nanoparticles," Acta Biomaterialia, vol. 4, no. 3, pp. 707-716, 2008.

[92] M. Agarwala, B. Choudhury, and R. N. S. Yadav, "Comparative study of antibiofilm activity of copper oxide and iron oxide nanoparticles against multidrug resistant biofilm forming uropathogens," Indian Journal of Microbiology, vol. 54, no. 3, pp. 365-368, 2014.

[93] J. Lellouche, A. Friedman, J. P. Lellouche, A. Gedanken, and E. Banin, "Improved antibacterial and antibiofilm activity of magnesium fluoride nanoparticles obtained by water-based ultrasound chemistry," Nanomedicine: Nanotechnology, Biology, and Medicine, vol. 8, no. 5, pp. 702-711, 2012.

[94] J. Lellouche, E. Kahana, S. Elias, A. Gedanken, and E. Banin, "Antibiofilm activity of nanosized magnesium fluoride," Biomaterials, vol. 30, no. 30, pp. 5969-5978, 2009.

[95] J. Lellouche, A. Friedman, R. Lahmi, A. Gedanken, and E. Banin, "Antibiofilm surface functionalization of catheters by magnesium fluoride nanoparticles," International Journal of Nanomedicine, vol. 7, pp. 1175-1188, 2012.

[96] H. Park, H.-J. Park, J. A. Kim et al., "Inactivation of Pseudomonas aeruginosa PA01 biofilms by hyperthermia using superparamagnetic nanoparticles," Journal of Microbiological Methods, vol. 84, no. 1, pp. 41-45, 2011.

[97] N. G. Durmus, E. N. Taylor, K. M. Kummer, and T. J. Webster, "Enhanced efficacy of superparamagnetic iron oxide nanoparticles against antibiotic-resistant biofilms in the presence of metabolites," Advanced Materials (Deerfield Beach, Fla), vol. 25, no. 40, pp. 5706-5713, 2013.

[98] E. N. Taylor, K. M. Kummer, N. G. Durmus, K. Leuba, K. M. Tarquinio, and T. J. Webster, "Superparamagnetic iron oxide nanoparticles (SPION) for the treatment of antibiotic-resistant biofilms," Small, vol. 8, no. 19, pp. 3016-3027, 2012.

[99] E. N. Taylor and T. J. Webster, "The use of superparamagnetic nanoparticles for prosthetic biofilm prevention," International Journal of Nanomedicine, vol. 4, pp. 145-152, 2009.

[100] A. W. Carpenter and M. H. Schoenfisch, "Nitric oxide release: part II. Therapeutic applications," Chemical Society Reviews, vol. 41, no. 10, pp. 3742-3752, 2012.

[101] D. O. Schairer, J. S. Chouake, J. D. Nosanchuk, and A. J. Friedman, "The potential of nitric oxide releasing therapies as antimicrobial agents.," Virulence, vol. 3, no. 3, pp. 271-279, 2012.

[102] D. L. Slomberg, Y. Lu, A. D. Broadnax, R. A. Hunter, A. W. Carpenter, and M. H. Schoenfisch, "Role of size and shape on biofilm eradication for nitric oxide-releasing silica nanoparticles," ACS Applied Materials and Interfaces, vol. 5, no. 19, pp. 9322-9329, 2013.

[103] A. J. Kutner and A. J. Friedman, "Use of nitric oxide nanoparticulate platform for the treatment of skin and soft tissue infections," Wiley Interdisciplinary Reviews: Nanomedicine and Nanobiotechnology, vol. 5, no. 5, pp. 502-514, 2013.

[104] G. Han, L. R. Martinez, M. R. Mihu, A. J. Friedman, J. M. Friedman, and J. D. Nosanchuk, "Nitric oxide releasing nanoparticles are therapeutic for Staphylococcus aureus abscesses in a murine model of infection," PLoS ONE, vol. 4, no. 11, Article ID e7804, 2009.

[105] L. R. Martinez, G. Han, M. Chacko et al., "Antimicrobial and healing efficacy of sustained release nitric oxide nanoparticles against Staphylococcus aureus skin infection," The Journal of Investigative Dermatology, vol. 129, no. 10, pp. 2463-2469, 2009.

[106] R. Weller and M. J. Finnen, "The effects of topical treatment with acidified nitrite on wound healing in normal and diabetic mice," Nitric Oxide, vol. 15, no. 4, pp. 395-399, 2006.

[107] E. M. Hetrick, J. H. Shin, H. S. Paul, and M. H. Schoenfisch, "Anti-biofilm efficacy of nitric oxide-releasing silica nanoparticles," Biomaterials, vol. 30, no. 14, pp. 2782-2789, 2009.

[108] N. Barraud, D. J. Hassett, S.-H. Hwang, S. A. Rice, S. Kjelleberg, and J. S. Webb, "Involvement of nitric oxide in biofilm dispersal of Pseudomonas aeruginosa," Journal of Bacteriology, vol. 188, no. 21, pp. 7344-7353, 2006.

[109] J. Chouake, D. Schairer, A. Kutner et al., "Nitrosoglutathione generating nitric oxide nanoparticles as an improved strategy for combating Pseudomonas aeruginosa-infected wounds," Journal of Drugs in Dermatology, vol. 11, no. 12, pp. 1471-1477, 2012.

[110] Z. Qiu, Y. Yu, Z. Chen et al., "Nanoalumina promotes the horizontal transfer of multiresistance genes mediated by plasmids across genera," Proceedings of the National Academy of Sciences of the United States of America, vol. 109, no. 13, pp. 4944-4949, 2012.

[111] J. J. Buckley, P. L. Gai, A. F. Lee, L. Olivi, and K. Wilson, "Silver carbonate nanoparticles stabilised over alumina nanoneedles exhibiting potent antibacterial properties," Chemical Communications, no. 34, pp. 4013-4015, 2008.

[112] M. A. Ansari, H. M. Khan, A. A. Khan, S. S. Cameotra, Q. Saquib, and J. Musarrat, "Interaction of $\mathrm{Al}_{2} \mathrm{O}_{3}$ nanoparticles with Escherichia coli and their cell envelope biomolecules," Journal of Applied Microbiology, vol. 116, pp. 772-783, 2014.

[113] J. A. Lichter and M. F. Rubner, "Polyelectrolyte multilayers with intrinsic antimicrobial functionality: the importance of mobile polycations," Langmuir, vol. 25, no. 13, pp. 7686-7694, 2009.

[114] A. Jain, L. S. Duvvuri, S. Farah, N. Beyth, A. J. Domb, and W. Khan, "Antimicrobial polymers," Advanced Healthcare Materials, vol. 3, no. 12, pp. 1969-1985, 2014.

[115] J. Hiraki, "Basic and applied studies on $\varepsilon$-polylysine," Journal of Antibacterial and Antifungal Agents, vol. 23, pp. 349-354, 1995.

[116] C. J. Waschinski and J. C. Tiller, "Poly(oxazoline)s with telechelic antimicrobial functions," Biomacromolecules, vol. 6, no. 1, pp. 235-243, 2005.

[117] E. B. Anderson and T. E. Long, "Imidazole- and imidazoliumcontaining polymers for biology and material science applications," Polymer, vol. 51, no. 12, pp. 2447-2454, 2010.

[118] C. Soykan, R. Coşkun, and A. Delibaş, "Microbial screening of copolymers of $\mathrm{N}$-vinylimidazole with phenacyl methacrylate: synthesis and monomer reactivity ratios," Journal of Macromolecular Science Part A: Pure and Applied Chemistry, vol. 42, no. 12, pp. 1603-1619, 2005.

[119] M. Albert, P. Feiertag, G. Hayn, R. Saf, and H. Hönig, "Structure-activity relationships of oligoguanidines-influence of counterion, diamine, and average molecular weight on biocidal activities," Biomacromolecules, vol. 4, no. 6, pp. 1811-1817, 2003.

[120] A. Muñoz-Bonilla and M. Fernández-García, "Polymeric materials with antimicrobial activity," Progress in Polymer Science, vol. 37, no. 2, pp. 281-339, 2012. 
[121] S. P. Denyer and G. S. A. B. Stewart, "Mechanisms of action of disinfectants," International Biodeterioration and Biodegradation, vol. 41, no. 3-4, pp. 261-268, 1998.

[122] G. Sauvet, W. Fortuniak, K. Kazmierski, and J. Chojnowski, "Amphiphilic block and statistical siloxane copolymers with antimicrobial activity," Journal of Polymer Science Part A: Polymer Chemistry, vol. 41, no. 19, pp. 2939-2948, 2003.

[123] E.-S. Park, W.-S. Moon, M.-J. Song, M.-N. Kim, K.-H. Chung, and J.-S. Yoon, "Antimicrobial activity of phenol and benzoic acid derivatives," International Biodeterioration and Biodegradation, vol. 47, no. 4, pp. 209-214, 2001.

[124] H. K. Jung, E. S. Park, H. S. Jae et al., "Antimicrobial activity of phydroxyphenyl acrylate derivatives," Journal of Agricultural and Food Chemistry, vol. 52, no. 25, pp. 7480-7483, 2004.

[125] E. Subramanyam, S. Mohandoss, and H.-W. Shin, "Synthesis, characterization, and evaluation of antifouling polymers of 4acryloyloxybenzaldehyde with methyl methacrylate," Journal of Applied Polymer Science, vol. 112, no. 5, pp. 2741-2749, 2009.

[126] T. Nonaka, L. Hua, T. Ogata, and S. Kurihara, "Synthesis of water-soluble thermosensitive polymers having phosphonium groups from methacryloyloxyethyl trialkyl phosphonium chlorides- $\mathrm{N}$-isopropylacrylamide copolymers and their functions," Journal of Applied Polymer Science, vol. 87, no. 3, pp. 386393, 2003.

[127] D. Chung, S. E. Papadakis, and K. L. Yam, "Evaluation of a polymer coating containing triclosan as the antimicrobial layer for packaging materials," International Journal of Food Science and Technology, vol. 38, no. 2, pp. 165-169, 2003.

[128] H. Zhang, D. Wang, R. Butler et al., "Formation and enhanced biocidal activity of water-dispersable organic nanoparticles," Nature Nanotechnology, vol. 3, no. 8, pp. 506-511, 2008.

[129] M. Bankova, N. Manolova, N. Markova, T. Radoucheva, K. Dilova, and I. Rashkov, "Hydrolysis and antibacterial activity of polymers containing 8-quinolinyl acrylate," Journal of Bioactive and Compatible Polymers, vol. 12, no. 4, pp. 294-307, 1997.

[130] C. Zhou, X. Qi, P. Li et al., "High potency and broad-spectrum antimicrobial peptides synthesized via ring-opening polymerization of $\alpha$-aminoacid-N-carboxyanhydrides," Biomacromolecules, vol. 11, no. 1, pp. 60-67, 2010.

[131] C. E. Carraher Jr., T. S. Sabir, M. R. Roner et al., "Synthesis of organotin polyamine ethers containing acyclovir and their preliminary anticancer and antiviral activity," Journal of Inorganic and Organometallic Polymers and Materials, vol. 16, no. 3, pp. 249-257, 2006.

[132] E.-R. Kenawy, S. D. Worley, and R. Broughton, "The chemistry and applications of antimicrobial polymers: a state-of-the-art review," Biomacromolecules, vol. 8, no. 5, pp. 1359-1384, 2007.

[133] D. K. Shvero, N. Zatlsman, R. Hazan, E. I. Weiss, and N. Beyth, "Characterisation of the antibacterial effect of polyethyleneimine nanoparticles in relation to particle distribution in resin composite," Journal of Dentistry, vol. 43, no. 2, pp. 287-294, 2015.

[134] D. Kesler Shvero, I. Abramovitz, N. Zaltsman, M. Perez Davidi, E. I. Weiss, and N. Beyth, "Towards antibacterial endodontic sealers using quaternary ammonium nanoparticles," International Endodontic Journal, vol. 46, no. 8, pp. 747-754, 2013.

[135] D.-S. Lee, J.-Y. Woo, C.-B. Ahn, and J.-Y. Je, "Chitosanhydroxycinnamic acid conjugates: preparation, antioxidant and antimicrobial activity," Food Chemistry, vol. 148, pp. 97-104, 2014.

[136] E. I. Rabea, M. E.-T. Badawy, C. V. Stevens, G. Smagghe, and W. Steurbaut, "Chitosan as antimicrobial agent: applications and mode of action," Biomacromolecules, vol. 4, no. 6, pp. 1457-1465, 2003.

[137] Y.-C. Chung, H.-L. Wang, Y.-M. Chen, and S.-L. Li, "Effect of abiotic factors on the antibacterial activity of chitosan against waterborne pathogens," Bioresource Technology, vol. 88, no. 3, pp. 179-184, 2003.

[138] F. K. Tavaria, E. M. Costa, E. J. Gens, F. X. Malcata, and M. E. Pintado, "Influence of abiotic factors on the antimicrobial activity of chitosan," The Journal of Dermatology, vol. 40, no. 12, pp. 1014-1019, 2013.

[139] S. Tin, K. R. Sakharkar, C. S. Lim, and M. K. Sakharkar, "Activity of Chitosans in combination with antibiotics in Pseudomonas aeruginosa," International Journal of Biological Sciences, vol. 5, no. 2, pp. 153-160, 2009.

[140] M. Ibrahim, Z. Tao, A. Hussain et al., "Deciphering the role of Burkholderia cenocepacia membrane proteins in antimicrobial properties of chitosan," Archives of Microbiology, vol. 196, no. 1, pp. 9-16, 2014.

[141] J. Ponti, E. Sabbioni, B. Munaro et al., "Genotoxicity and morphological transformation induced by cobalt nanoparticles and cobalt chloride: an in vitro study in Balb/3T3 mouse fibroblasts," Mutagenesis, vol. 24, no. 5, pp. 439-445, 2009.

[142] S. Dey, V. Bakthavatchalu, M. T. Tseng et al., "Interactions between SIRT1 and AP-1 reveal a mechanistic insight into the growth promoting properties of alumina $\left(\mathrm{Al}_{2} \mathrm{O}_{3}\right)$ nanoparticles in mouse skin epithelial cells," Carcinogenesis, vol. 29, no. 10, pp. 1920-1929, 2008.

[143] S. Arora, J. Jain, J. M. Rajwade, and K. M. Paknikar, "Cellular responses induced by silver nanoparticles: in vitro studies," Toxicology Letters, vol. 179, no. 2, pp. 93-100, 2008.

[144] M. Simon, P. Barberet, M.-H. Delville, P. Moretto, and H. Seznec, "Titanium dioxide nanoparticles induced intracellular calcium homeostasis modification in primary human keratinocytes. Towards an in vitro explanation of titanium dioxide nanoparticles toxicity," Nanotoxicology, vol. 5, no. 2, pp. 125-139, 2011.

[145] P. R. Chandran, M. Naseer, N. Udupa, and N. Sandhyarani, "Size controlled synthesis of biocompatible gold nanoparticles and their activity in the oxidation of NADH," Nanotechnology, vol. 23, no. 1, Article ID 015602, 2012.

[146] L.-H. Li, H.-W. Kim, S.-H. Lee, Y.-M. Kong, and H.-E. Kim, "Biocompatibility of titanium implants modified by microarc oxidation and hydroxyapatite coating," Journal of Biomedical Materials Research Part A, vol. 73, no. 1, pp. 48-54, 2005.

[147] K. S. Brammer, S. Oh, J. O. Gallagher, and S. Jin, "Enhanced cellular mobility guided by $\mathrm{TiO}_{2}$ nanotube surfaces," Nano Letters, vol. 8, no. 3, pp. 786-793, 2008.

[148] G. Giavaresi, R. Giardino, L. Ambrosio et al., "In vitro biocompatibility of titanium oxide for prosthetic devices nanostructured by low pressure metal-organic chemical vapor deposition," The International Journal of Artificial Organs, vol. 26, no. 8, pp. 774-780, 2003.

[149] S. Oh, C. Daraio, L. H. Chen, T. R. Pisanic, R. R. Fiñones, and S. Jin, "Significantly accelerated osteoblast cell growth on aligned $\mathrm{TiO}_{2}$ nanotubes," Journal of Biomedical Materials Research: Part $A$, vol. 78, no. 1, pp. 97-103, 2006.

[150] Y.-C. Chung, I.-H. Chen, and C.-J. Chen, "The surface modification of silver nanoparticles by phosphoryl disulfides for improved biocompatibility and intracellular uptake," Biomaterials, vol. 29, no. 12, pp. 1807-1816, 2008. 
[151] T. K. Jain, M. K. Reddy, M. A. Morales, D. L. Leslie-Pelecky, and V. Labhasetwar, "Biodistribution, clearance, and biocompatibility of iron oxide magnetic nanoparticles in rats," Molecular Pharmaceutics, vol. 5, no. 2, pp. 316-327, 2008.

[152] J. Sun, S. Zhou, P. Hou et al., "Synthesis and characterization of biocompatible $\mathrm{Fe}_{3} \mathrm{O}_{4}$ nanoparticles," Journal of Biomedical Materials Research Part A, vol. 80, no. 2, pp. 333-341, 2007.

[153] Z. Li, R. Yang, M. Yu, F. Bai, C. Li, and Z. L. Wang, "Cellular level biocompatibility and biosafety of $\mathrm{ZnO}$ nanowires," The Journal of Physical Chemistry C, vol. 112, no. 51, pp. 20114-20117, 2008.

[154] P. Maneewattanapinyo, W. Banlunara, C. Thammacharoen, S. Ekgasit, and T. Kaewamatawong, "An evaluation of acute toxicity of colloidal silver nanoparticles," The Journal of Veterinary Medical Science, vol. 73, no. 11, pp. 1417-1423, 2011.

[155] W. H. de Jong, W. I. Hagens, P. Krystek, M. C. Burger, A. J. A. M. Sips, and R. E. Geertsma, "Particle size-dependent organ distribution of gold nanoparticles after intravenous administration," Biomaterials, vol. 29, no. 12, pp. 1912-1919, 2008.

[156] Y. Zhao and H. S. Nalwa, Eds., Nanotoxicology-Interactions of Nanomaterials with Biological Systems, SciTech Book News, 2008.

[157] B. Halliwell and J. Gutteridge, Free Radicals in Biology and Medicine, Oxford University Press, 4th edition, 2007.

[158] G. Oberdörster, E. Oberdörster, and J. Oberdörster, "Nanotoxicology: an emerging discipline evolving from studies of ultrafine particles," Environmental Health Perspectives, vol. 113, no. 7, pp. 823-839, 2005.

[159] E. Bermudez, J. B. Mangum, B. A. Wong et al., "Pulmonary responses of mice, rats, and hamsters to subchronic inhalation of ultrafine titanium dioxide particles," Toxicological Sciences, vol. 77, no. 2, pp. 347-357, 2004.

[160] E. Oberdörster, "Manufactured nanomaterials (fullerenes, C60) induce oxidative stress in the brain of juvenile largemouth bass," Environmental Health Perspectives, vol. 112, no. 10, pp. 10581062, 2004.

[161] D. B. Warheit, B. R. Laurence, K. L. Reed, D. H. Roach, G. A. M. Reynolds, and T. R. Webb, "Comparative pulmonary toxicity assessment of single-wall carbon nanotubes in rats," Toxicological Sciences, vol. 77, no. 1, pp. 117-125, 2004.

[162] E. J. Petersen and B. C. Nelson, "Mechanisms and measurements of nanomaterial-induced oxidative damage to DNA," Analytical and Bioanalytical Chemistry, vol. 398, no. 2, pp. 613-650, 2010.

[163] L. A. Esposito, S. Melov, A. Panov, B. A. Cottrell, and D. C. Wallace, "Mitochondrial disease in mouse results in increased oxidative stress," Proceedings of the National Academy of Sciences of the United States of America, vol. 96, no. 9, pp. 4820-4825, 1999.

[164] I. G. Kirkinezos and C. T. Moraes, "Reactive oxygen species and mitochondrial diseases," Seminars in Cell and Developmental Biology, vol. 12, no. 6, pp. 449-457, 2001.

[165] R. M. Adibhatla and J. F. Hatcher, "Lipid oxidation and peroxidation in CNS Health and disease: from molecular mechanisms to therapeutic opportunities," Antioxidants and Redox Signaling, vol. 12, no. 1, pp. 125-169, 2010.

[166] N. Beyth, Y. Houri-Haddad, L. Baraness-Hadar, I. YudovinFarber, A. J. Domb, and E. I. Weiss, "Surface antimicrobial activity and biocompatibility of incorporated polyethylenimine nanoparticles," Biomaterials, vol. 29, no. 31, pp. 4157-4163, 2008.

[167] I. Abramovitz, N. Beyth, G. Weinberg et al., "In Vitro biocompatibility of endodontic sealers incorporating antibacterial nanoparticles," Journal of Nanomaterials, vol. 2012, Article ID 858073, 9 pages, 2012.
[168] C. Srisitthiratkul, V. Pongsorrarith, and N. Intasanta, "The potential use of nanosilver-decorated titanium dioxide nanofibers for toxin decomposition with antimicrobial and self-cleaning properties," Applied Surface Science, vol. 257, no. 21, pp. 8850-8856, 2011.

[169] R. M. El-Shishtawy, A. M. Asiri, N. A. M. Abdelwahed, and M. M. Al-Otaibi, "In situ production of silver nanoparticle on cotton fabric and its antimicrobial evaluation," Cellulose, vol. 18, no. 1, pp. 75-82, 2011.

[170] S. Jadhav, S. Gaikwad, M. Nimse, and A. Rajbhoj, “Copper oxide nanoparticles: synthesis, characterization and their antibacterial activity," Journal of Cluster Science, vol. 22, no. 2, pp. 121-129, 2011.

[171] T. Gordon, B. Perlstein, O. Houbara, I. Felner, E. Banin, and S. Margel, "Synthesis and characterization of zinc/iron oxide composite nanoparticles and their antibacterial properties," Colloids and Surfaces A: Physicochemical and Engineering Aspects, vol. 374, no. 1-3, pp. 1-8, 2011.

[172] F. Al-Hazmi, F. Alnowaiser, A. A. Al-Ghamdi, M. M. Aly, R. M. Al-Tuwirqi, and F. El-Tantawy, "A new large-scale synthesis of magnesium oxide nanowires: structural and antibacterial properties," Superlattices and Microstructures, vol. 52, no. 2, pp. 200-209, 2012.

[173] N. Beyth, I. Yudovin-Farber, R. Bahir, A. J. Domb, and E. I. Weiss, "Antibacterial activity of dental composites containing quaternary ammonium polyethylenimine nanoparticles against Streptococcus mutans," Biomaterials, vol. 27, no. 21, pp. 39954002, 2006.

[174] Y. Hu, Y. Du, J. Yang, J. F. Kennedy, X. H. Wang, and L. S. Wang, "Synthesis, characterization and antibacterial activity of guanidinylated chitosan," Carbohydrate Polymers, vol. 67, no. 1, pp. 66-72, 2007. 


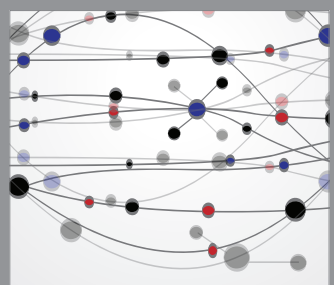

The Scientific World Journal
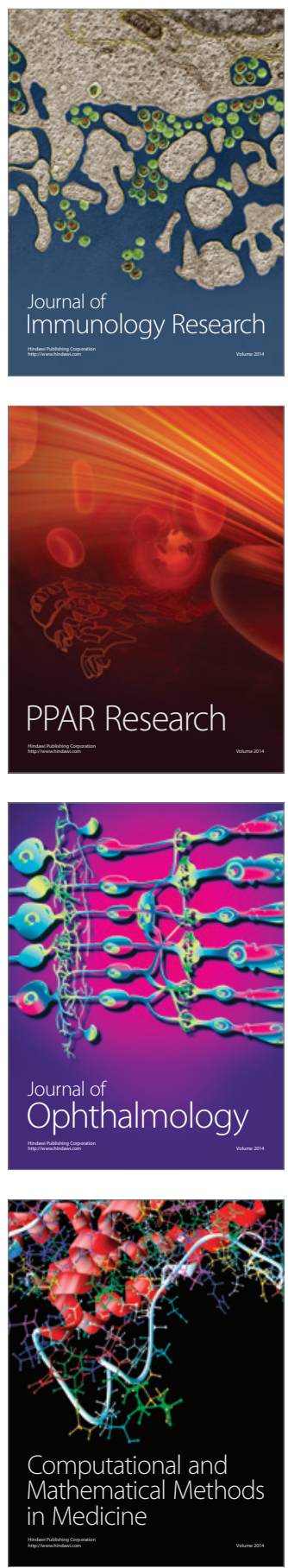

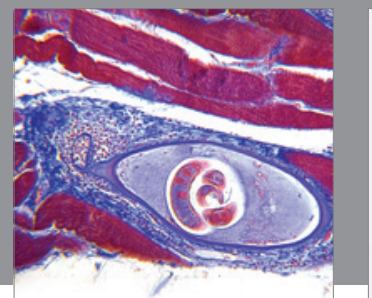

Gastroenterology

Research and Practice
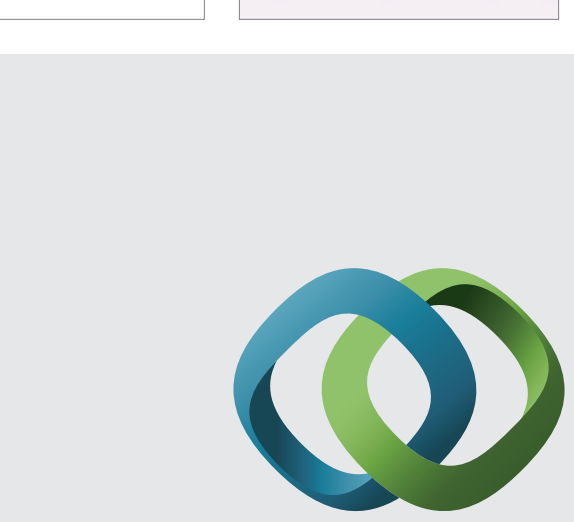

\section{Hindawi}

Submit your manuscripts at

http://www.hindawi.com
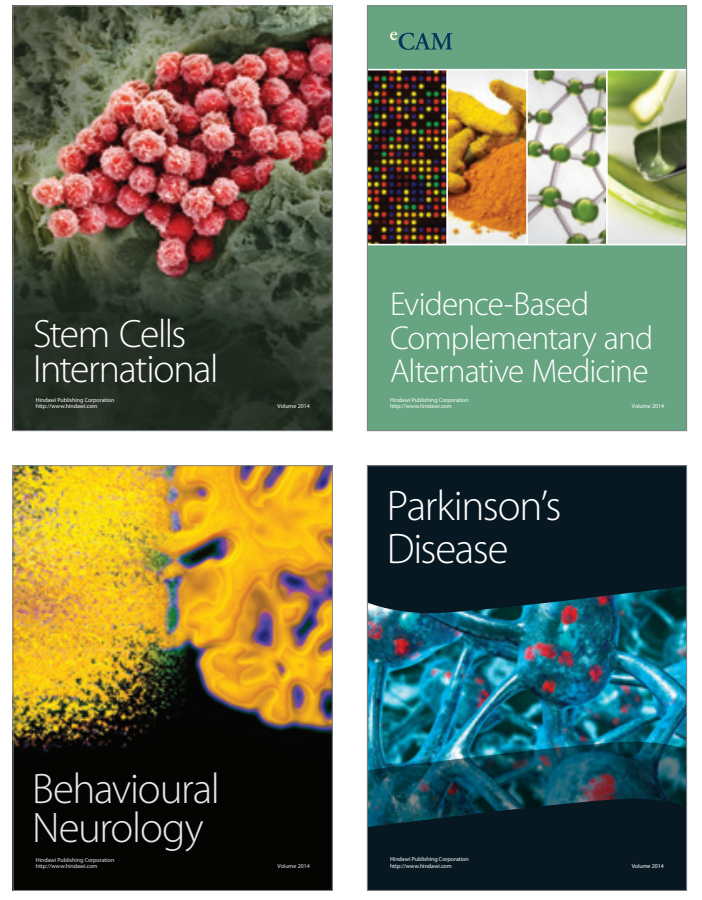
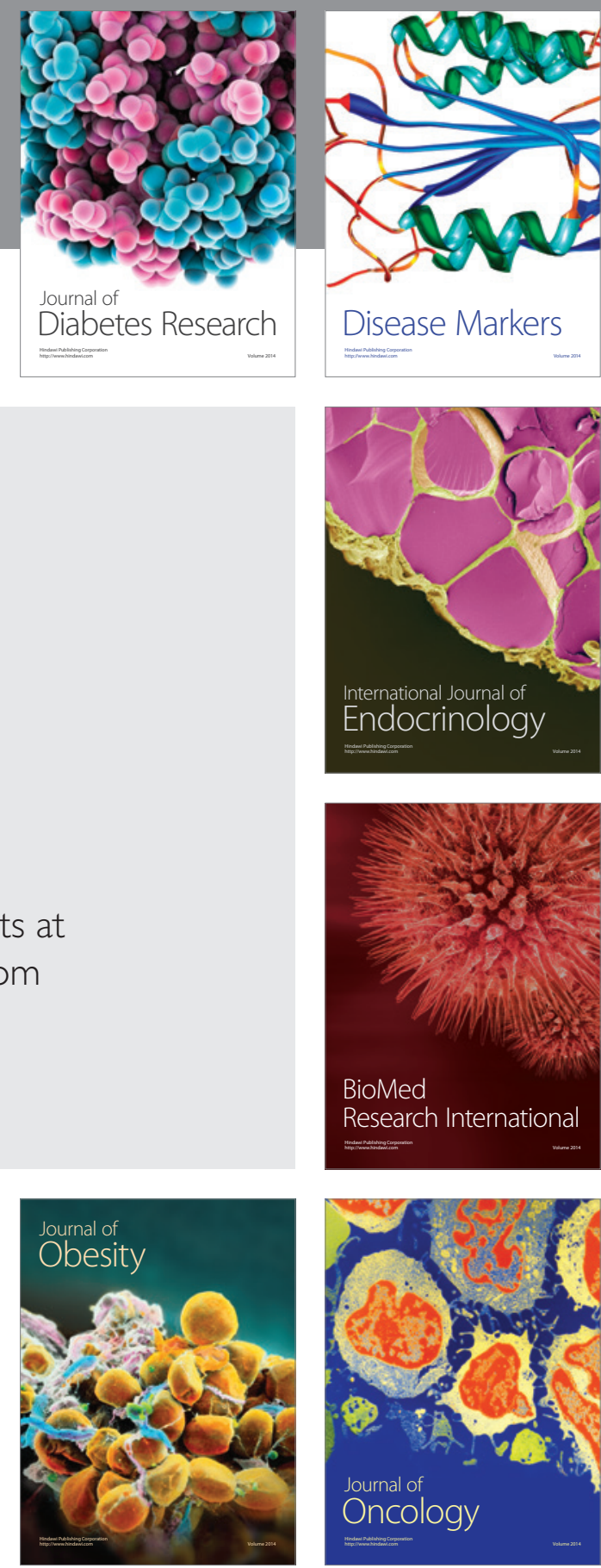

Disease Markers
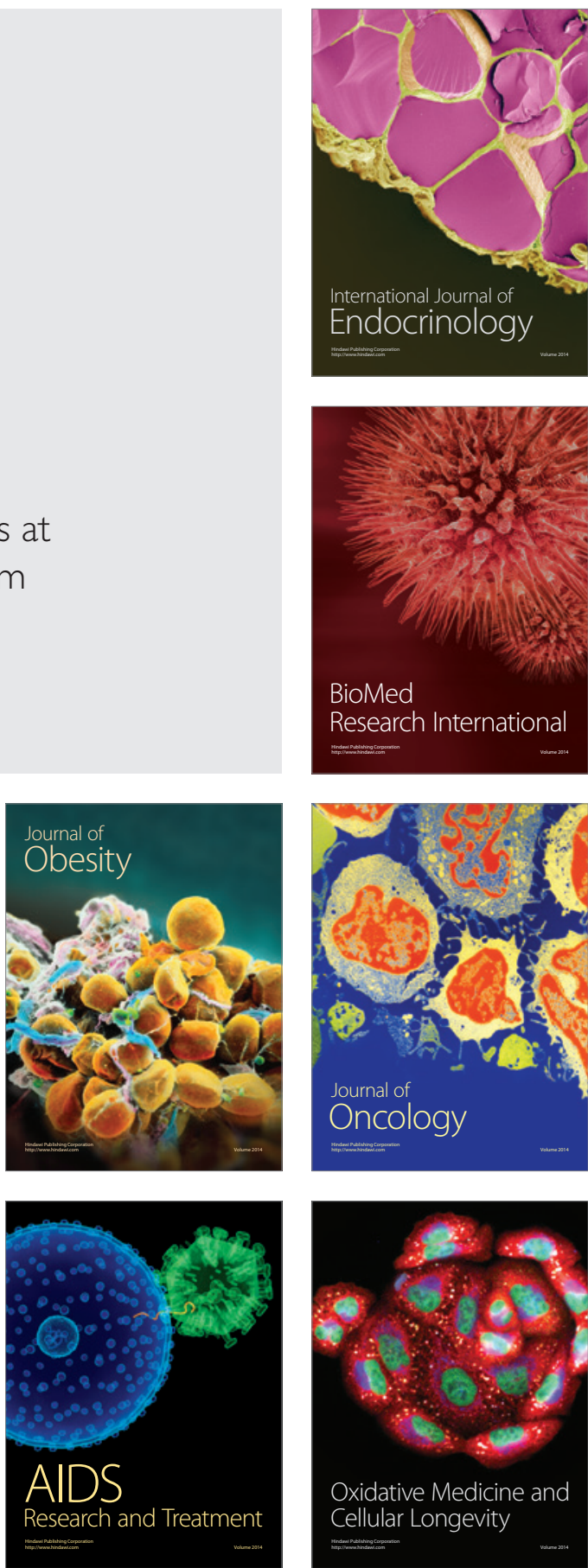